\title{
Novel targets for delaying aging: The importance of the liver and advances in drug delivery
}

\author{
Nicholas J. Hunt ${ }^{\mathrm{a}, \mathrm{b}, \mathrm{c}}$, Peter A.G. McCourt ${ }^{\mathrm{c}, \mathrm{d}}$, David G. Le Couteur ${ }^{\mathrm{a}, \mathrm{b}, \mathrm{c}}$, Victoria C. Cogger ${ }^{\mathrm{a}, \mathrm{b}, \mathrm{c}, *}$ \\ a Biogerontology Group, Concord General Hospital, ANZAC Research Institute, Australia \\ b Aging and Alzheimer's Institute, Concord General Hospital, Centre for Education and Research on Aging, Australia \\ ${ }^{c}$ Nutritional Ecology Group, Charles Perkins Centre, University of Sydney, Australia \\ d Department of Medical Biology, University of Tromsø, Norway
}

\section{A R T I C L E INFO}

Article history:

Received 22 June 2018

Received in revised form 14 September 2018

Accepted 18 September 2018

Available online xxx

\section{Keywords:}

Nutrient sensing pathways

Hepatic

Nanoparticle

Review

Novel

Nicotinamide

Quantum dot

LSEC

Metabolism

\section{A B S T R A C T}

Age-related changes in liver function have a significant impact on systemic aging and susceptibility to agerelated diseases. Nutrient sensing pathways have emerged as important targets for the development of drugs that delay aging and the onset age-related diseases. This supports a central role for the hepatic regulation of metabolism in the association between nutrition and aging. Recently, a role for liver sinusoidal endothelial cells (LSECs) in the relationship between aging and metabolism has also been proposed. Agerelated loss of fenestrations within LSECs impairs the transfer of substrates (such as lipoproteins and insulin) between sinusoidal blood and hepatocytes, resulting in post-prandial hyperlipidemia and insulin resistance. Targeted drug delivery methods such as nanoparticles and quantum dots will facilitate the direct delivery of drugs that regulate fenestrations in LSECs, providing an innovative approach to ameliorating age-related diseases and increasing healthspan.

(C) 2018 .

\section{Introduction}

Advances in the treatment and prevention of infectious diseases, together with increased standards of living have led to a rapid increase in life expectancy over the last century [1]. However, this has driven a significant increase in the number of older people with multimorbidity and disability that impair quality of life and productivity [2]. Therefore, research in aging biology largely focusses on delaying

\footnotetext{
Abbreviations: AMPK, AMP-activated protein kinase; Cd, cadmium; CR, caloric restriction; FOXO, forkhead box O transcription factor; FSA, formaldehyde treated BSA/HAS; GH, growth hormone; HA, hyaluronan; HOMA-IR, homeostatic model of assessment on insulin resistance; IGF-1, insulin-like growth factor 1; IRS1, insulin receptor subunit 1; ISS, insulin/IGF-1 signaling; LKB1, liver kinase B1; LSEC, liver sinusoidal endothelial cell; mTOR, mechanistic target of rapamycin; MEND, multifunctional envelope-like nanocapsule device; $\mathrm{NAD}^{+}$, nicotinamide adenine dinucleotide; NAM, nicotinamide; NMN, nicotinamide mononucleotide; $\mathrm{NR}$, nicotinamide riboside; $\mathrm{PEG}$, polyethylene glycol; PINP, pro-collagen I N-terminal peptides; PI3K, phosphatidylinositol 3-kinase; PKB, protein kinase B; QDs, quantum dots; S, sulphide; SIRT1, sirtuin 1; TRAIL, TNF-related apoptosis inducing ligand; Te, telluride.

* Corresponding author at: Biogerontology Group, Concord General Hospital, ANZAC Research Institute, Australia.

Email address: victoria.cogger@sydney.edu.au (V.C. Cogger)
}

aging in order to increase healthspan, the period of life spent free from, or with limited, disease burden $[3,4]$.

\section{Aging and the liver}

Aging is usually considered to be a process of gradual physiological deterioration experienced over time by most living things, leading to increased risk of disease and death. Aging is a heterogeneous and heterochronic process that can be difficult to evaluate because there are different rates of aging between species and within individuals of the same species, as well as between tissues in the same organism [5]. This heterogeneity has in part prevented the identification of a single marker and/or cause of aging, however there are several biological processes that have been identified as modulators of the aging process [5]. Described as the "hallmarks of aging", these processes include: genomic instability, telomere attrition, epigenetic alterations, loss of proteostasis, deregulated nutrient sensing, mitochondrial dysfunction, cellular senescence, stem cell exhaustion and altered intercellular communication [6].

One method of evaluating the rate of aging that encompasses many of its manifestations is the "transcriptome age" [7]. Age-related changes in the "transcriptome" of whole blood correlate better than chronological age with risk factors for cardiometabolic disease and death including cholesterol levels, body mass index, blood pressure and fasting glucose $[8,9]$. Studies such as these highlight the conver- 
gence of many aging mechanisms with cardiometabolic dysfunction [10]. This importance of metabolic pathways in aging biology is evidenced by the fact that the most robust intervention that delays aging is the nutritional intervention called "caloric restriction" (CR). First described in 1935 by Clive McKay et al. [11], CR is usually defined as a reduction in total calorie intake by $20-40 \%$ with micronutrient supplementation to prevent specific malnutrition disorders. Lifelong $\mathrm{CR}$ increases mean and maximal lifespan by $30-50 \%$ in rodents, dogs, flies, yeast, worms, monkeys and prokaryotes [2]. There is also limited evidence in humans that CR influences life expectancy and reduces the development of diseases [12] as well as the aging process itself [13]. Mice that are subjected to CR are leaner, more insulin sensitive, glucose tolerant and have reduced incidence of disease [29]. The effects of CR on aging are conserved across a range of species, indicating that there are fundamental cellular pathways linking nutrition with aging and health. Research in this area has led to the identification of several key nutrient sensing pathways that regulate aging (insulin/IGF1/GH signaling, SIRT1, AMPK and mTOR) [2], which in vertebrates are most strategically located in the liver, because it is the master regulator organ of systemic metabolism.

The liver regulates most metabolic pathways including glucose metabolism via glycolysis, glucose uptake and gluconeogenesis [14]; the formation and packaging of cholesterol and other lipids; and insulin sensitivity (Table 1) $[15,16]$. Ingested substances that are absorbed from the gut travel to the liver via the portal vein [17], which

Table 1

Aging and hepatic metabolism, effects of caloric restriction and drug treatments

Summary of age-related changes in the liver and treatments with caloric restriction and drugs that delays the aging process

Reference

Increased protein synthesis and burden of misfolded [189]

proteins producing oxidative stress and damage occur in the liver proteome of aging mice. This burden is reduced following $40 \%$ CR or rapamycin

Increased lipogenesis gene expression, cholesterol synthesis and lipid storage are observed in the aging mice liver. CR promotes the reprogramming of mice mice liver. CR
liver lipidome

Decreased hepatic autophagy has been demonstrated in multiple species with age, impairment leads to accumulation intracellular oxidative proteins, lipid droplets, lipofuscin and impaired mitochondrial function. Hepatic amino acid, glucose and free fatty acid metabolism are impaired. Acceleration of hepatic related diseases. Resveratrol $(200 \mathrm{mg} / \mathrm{kg})$ and $30 \%$ CR have been shown to promote SIRT1 mediated autophagy and improve oxidative protein stress.

Insulin signalling and sensitivity is reduced in aging rats and mediated via visceral fat content. Treatmen with resveratrol, Metformin and CR promote increased insulin sensitivity in aged rats

Hepatic glycolysis, glycogenesis and glucose uptake are all decreased with aging. FOXO genetic manipulation demonstrates its role in hepatic gene regulation of gluconeogenesis, glycolysis and lipogenesis. SIRT1 and PGC-1 $\alpha$ activation promote increased gluconeogenesis and reduced glycolysis in the liver

SIRT1 and mitochondrial biogenesis are reduced in aging mice; SIRT1-mediated HIF-1 $\alpha$ and PGC-1 $\alpha$ activity regulate mitochondrial biogenesis. CR and resveratrol treatments promote improved mitochondrial function in aging mice

Aging mice livers demonstrate increased inflammation, cellular stress, and fibrosis, with decreased apoptosis, xenobiotic metabolism, cell-cycling and DNA replication genomic profiles. $40 \%$ CR for a month was shown to improve these profiles in mice. also contains pancreatic hormones including insulin, glucagon and Cpeptide $[18,19]$. The hepatic microvasculature is highly specialized to optimize the bidirectional exchange of substrates between blood and hepatocytes. The endothelial cells that line this sinusoidal microvasculature (the "hepatic sinusoids") are called liver sinusoidal endothelial cells (LSEC) and are perforated with pores called "fenestrations" that facilitate size-selective sieving of blood-borne molecules for uptake by hepatocytes $[20,21]$. The term "pseudocapillarization" refers to age-related changes in the LSEC including a reduction in the size and number of fenestrations, which leads to impaired uptake of some substrates. Old age is associated with reduction in liver metabolism due to three main factors: reduced metabolic capacity due to diminished liver size and/or enzyme activity; decreased liver blood flow; and reduced transfer of metabolites and molecules from the sinusoids to the hepatocytes $[22,23]$. Together, these changes impact many facets of hepatic metabolism of substrates such as lipoproteins, drugs and insulin [24-26] thus potentially contributing to insulin resistance, vascular disease and adverse drug reactions $[7,27,28]$.

Here we discuss these two hepatic drug targets - nutrient sensing pathway in hepatocytes; and fenestrations in LSECs - that might impact on systemic and hepatic aging. We also discuss the possibility of using nanomedicines to precisely deliver fenestration-active agents directly to the LSECs.

\section{Targeting the nutrient sensing pathways}

Nutrient sensing pathways regulate adaptive cellular responses to changing nutrient availability such as famine or food excess. During times of nutrient scarcity, these pathways promote the survival and resilience of an organism at the cost of reduced reproductive capacity. Presumably these pathways have evolved to promote reproduction only when there are sufficient nutrients to ensure the survival of offspring. In multicellular organisms nutrient sensing pathways form complex networks that detect, organize, use, reconstitute and metabolize nutrients [29]. The downstream physiological consequences of activating or antagonizing these pathways (for example by CR, or drugs that are thought to mimic CR) are shown in Table 1 [40]. Manipulation of these pathways through CR or genetic interventions has been shown to alter the biological process of aging, median and maximal lifespans and the incidence of many age-related diseases. The four canonical nutrient sensing pathways interact with each other and share many downstream targets that regulate cellular processes that are critical for aging including mitochondrial biogenesis, cellular metabolism, autophagy, DNA repair and expression, and translation (Figure 1).

With increasing age, there are changes in the expression and activity of the four nutrient sensing pathways: insulin/IGF-1, mTOR, AMPK, and the Sirtuin $/ \mathrm{NAD}^{+}$pathways $[16,30,31]$. Within the key organs involved in homeostatic metabolic regulation - liver, pancreas, muscle and fat - these changes are associated with other aging processes such as oxidative stress [32] and inflammation [29,33,34]. Together these processes in these organs contribute to impaired systemic metabolism, which in turn is linked mechanistically with diabetes, cardiovascular disease, cancers and neurodegeneration $[5,31,33,35]$. Although the major interventions used are CR and genetic overexpression or knockout models [36,37], recently pharmacological manipulation of these pathways with agents such as metformin, rapamycin and resveratrol, has been shown to delay the aging process, at least in laboratory animal models [38-40].

Therapeutic agents recapitulate the effects of CR on aging have been termed "CR-mimetics" [41] which primarily target individual components of the nutrient sensing pathways. Although these drugs 
have been used to treat individual diseases in the past, it is possible that their beneficial effect is in part secondary to delay the effect of aging on these diseases. Moreover, in some studies in animal models, CR mimetics have been found to increase median and maximal lifespan, probably by delaying the onset of aging $[16,42,43]$. lows:

The main features of these nutrient sensing pathways are as fol-

\subsection{Mechanistic target of rapamycin (mTOR)}

mTOR is a serine/threonine protein kinase that regulates cell growth, proliferation, motility, protein synthesis and autophagy. mTOR integrates input from various pathways, including insulin and IGF-1, and responds to dietary protein, particularly the branchedchain amino acids. mTOR exists in two different complexes mTORC1 and mTORC2, which are differentiated by their accessory proteins, Raptor and Rictor, and only mTORC1 is sensitive to amino acids [44]. Rapamycin is a potent inhibitor of mTOR that was initially utilized as an immunosuppressive drug for patients following renal transplants. It has now been associated with increased lifespan in mice fed standard diets $[45,46]$ and human studies into the effects of rapamycin on healthy elderly patients are currently being performed $[30,47]$.

\subsection{5' Adenosine monophosphate-activated protein kinase (AMPK)}

AMPK regulates cellular uptake of glucose, $\beta$-oxidation of fatty acids, the glucose transporter 4 (GLUT4), and mitochondrial biogenesis. AMPK is activated in response to increased cellular AMP:ATP ratio. CR is associated with increased AMPK activity as a consequence of reduced energy intake. Metformin enhances lifespan in mice and this is accompanied by an increase in AMPK activity [39]. In humans, metformin has been shown to reduce the progression of diabetic impairment of glucose tolerance by $31 \%$, reduce atherosclerosis development [48-50] and a systematic review has demonstrated improved cardiovascular mortality by $25 \%$ [51,52]. Additionally a recent systematic review found that metformin promotes a significantly lower mortality in diabetic patients compared to non-diabetics and also diabetics that were not on metformin [53]. Human observational studies have concluded that metformin decreases the risk of the most common diseases of aging: cardiovascular disease [54-56], cancer [57], depression [58], frailty [54], mild cognitive impairment [59] and dementia $[60,61]$. Clinical trials in humans to evaluate its effects on disease susceptibility and aging biology (included transcriptome) are planned.

\subsection{Sirtuin pathway (SIRT1)}

Sirtuins are class III histone deacetylases that require $\mathrm{NAD}^{+}$as a cofactor. $\mathrm{CR}$ increases cellular $\mathrm{NAD}^{+}$as a consequence of reduced energy intake, thereby activating sirtuins. While the sirtuin family consists of seven members [62], in mammals, the key aging homolog is SIRT1 which deacetylates key histone residues involved in the regulation of transcription and multiple non-histone protein targets relevant to aging (p53, FOXO, PGC-1 $\alpha, \mathrm{NF}-\mathrm{\kappa B}$ ) [37,63]. A number of pharmacological agents that allosterically activate SIRT1 delay aging (Sirtuin Activating Compounds, known as STACs) including resveratrol and SRT2014 [40,64-67]. STACs promote allosteric activation of SIRT1 and differ in their potency and optimization in the activation of sirtuin [68]. STACs mimic CR, increase mitochondrial function and protect against metabolic and cardiovascular disease progression by reducing metabolic risk factors $[66,68]$. Notably resveratrol increased lifespan in mice fed a high fat diet [65] but not in mice on standard chow where only health benefits were observed $[46,69]$. This suggests that activation of the SIRT1 pathway may have its greatest effect on aging where there is high energy intake and greatest inhibition of SIRT activity. In addition, activation of SIRT1 with resveratrol treatment in vitro promoted endothelial protection via KLF-2 and MAPK5 [70].

A comprehensive review of human clinical trials, has demonstrated inconsistent findings in older people, with some showing health benefits, particularly in older humans with multimorbidities such as type II diabetes, non-alcoholic fatty liver disease (NAFLD) and coronary artery disease [71-78]. The dose, duration and the source of resveratrol has varied across many of the trials and might account for some of the inconsistencies seen in aging human studies. More recently nicotinamide mononucleotide (NMN), and nicotinamide riboside (NR), biosynthetic $\mathrm{NAD}^{+}$metabolites have been investigated for their ability to augment $\mathrm{NAD}^{+}$blood levels [79].

\subsection{Insulin/IGF-1signaling pathway (ISS)}

The insulin/ IGF-1 signaling pathway is continuously modulated by dietary nutrient status: plasma concentrations of protein (IGF-1) and sugars (insulin) and additionally by the levels of circulating growth hormone $(\mathrm{GH})$ [30]. Insulin release is stimulated by glucose and branched-chain amino acids. GH stimulates hepatic production of IGF-1 and acts on the IIS pathway to modulate insulin sensitivity [80]. Lower levels of insulin, IGF-1 and GH induced by either genetic variability or low energy diets are associated with increased lifespan across taxa and including humans [36].

\subsection{Recent additions to the classic pathways}

Autophagy is an essential cellular process that promotes cell survival, especially as a cellular starvation response, and regulates homeostasis. Autophagy is upregulated in the setting of low ATP and insulin, reduced growth factor stimulation and JNK1-Beclin-1 dependent cellular stress [81-84]. It facilitates the degradation of unnecessary and dysfunctional cellular products, liberating cellular stores of energy $[29,85]$. It has previously been highlighted in a review by Gracia-Sancho, et al. [81] that autophagy has an important role in inhibiting the development of liver diseases such as NAFLD, however hallmarks of NAFLD: hyperglycemia and impaired hepatocellular clearance of lipids impairs autophagy, suggesting that targeting autophagy pathways may be beneficial in the treatment of NAFLD and other fatty liver disorders.

Another recent potential addition to these four classical nutrientsensing pathways is Fibroblast Growth Factor 21 (FGF21). FGF21 is produced by the liver and is increased in response to acute starvation, with a recent study showing that low protein intake is the major stimulant for its expression and blood levels [86,87]. It regulates several metabolic functions (gluconeogenesis, mitochondrial activity, ketogenesis, lipid metabolism) which impact on age-related health. FGF21 interacts with the other nutrient-sensing pathways by activating AMPK and SIRT1 [88], suggesting a key role for FGF21 in linking nutrition and aging. Paradoxically in humans, higher levels of FGF21 are associated with obesity and diabetes, probably reflecting FGF21 resistance in these conditions. The role of FGF21 in aging and nutrition is now a key focus for aging research [89] . 


\section{Targeting the liver in aging}

As described above, the liver is a key regulator of metabolism, with significant age-related changes in function secondary to reduced liver size and enzyme activity, blood flow and transendothelial transfer $[20,22,23,90-93]$. This impairs detoxification and clearance of various endobiotics (e.g. lipoproteins and insulin) [94] and xenobiotics (e.g. drugs, neurotoxins and carcinogens) [95]. Many processes contribute to reduced metabolic enzyme activity and cellular damage in the aging liver, including the effects of aging on oxidative stress, inflammation, stress responses [96], autophagy and apoptosis [96,97], and mitochondrial function [98]. The reduction in blood flow to the liver reflects a general down regulation of splanchnic blood flow in all abdominal organs rather than any specific hepatic effects on vascular resistance. The reduction in the transfer of substrates between blood and hepatocytes occurs mainly as a result of the loss of fenestrations associated with pseudocapillarization $[2,24,25,94,95,99]$. All these aging liver changes will impact on the responsiveness and activity of the nutrient sensing pathways.

Age-related changes in liver cells also contribute to the increasing risk of the development of liver diseases with older age. The accumulation of oxidative stress and age-related changes in inflammation favors the progression towards NAFLD, steatohepatitis and hepatocellular carcinoma [100]. The development of NAFLD involves impairment of LSEC functions through impaired regulation of nitric oxide synthase and loss of fenestrations, with these features developing prior to the rise seen in inflammatory markers [101-103]. This suggests that targeting LSECs may, in addition to promoting healthy aging, be relevant to preventing the development of NAFLD and its progression to steatohepatitis (Fig. 1).

\subsection{Liver sinusoidal endothelial cells}

LSECs have a highly specialised morphology. They are perforated by numerous nano-holes/pores [104-106], called fenestrations, with diameters in the range $50-200 \mathrm{~nm}$. Moreover, there is no underlying basement membrane in the extracellular space of Disse. LSECs possess highly efficient endocytic capacity, transcellular transportation and immune-mediated pathways [107-111] that also contribute to the transfer of substrates between the blood and space of Disse. LSECs retain blood cells within the sinusoidal lumen while allowing the bidirectional passage through the fenestrations of substances such as dissolved or albumin-bound drugs, proteins, lipoproteins, and small viruses (Fig. 2). Little is known about the dynamic structure and regulation of fenestrations. To date the majority of studies on LSEC fenestrations have utilized electron microscopy and fixed cells or tissue, but new super-resolution optical methods are now available [112-116], which can visualize fenestrations in unfixed and/or live LSEC, and their responses to stimuli over time $[112,115]$. This will facilitate the discovery and testing of drugs that can influence fenestrations.

LSEC are potent scavengers, belonging to the family of "scavenger endothelial cells" [110], which also includes bone marrow sinusoidal endothelial cells $[117,118]$ and choriocapillaris endothelial cells [119]. LSECs clear soluble waste including hyaluronan [120-123], advanced glycation end-products [109,124,125], immune complexes [126], collagen alpha-chains [127,128], oxLDL [129] or nano-particles $(<200 \mathrm{~nm})$ such as viruses [111] and quantum dots [130] via clathrin mediated endocytosis, while the liver resident macrophages (Küpffer cells) clear particulate matter larger than 200nm [110]. This division of labour is called the "dual-cell principle of waste clearance", a concept first introduced by Sørensen et al. [110]. With the sinusoidal surface area equal to the size of a tennis court, the liver sinusoid is the most potent scavenging system in the body. Consequently, the LSEC has become the bane of nano-particle and antisense oligonucleotide based therapies that aim to target other tissues [131], but it can be an advantage if the liver sinusoid itself is the target.

\subsection{Aging LSECS}

LSECs undergo morphological and functional transformations in disease and aging. One key change is the loss of fenestrations, termed "defenestration", often associated with the deposition of a basement membrane [132]. "Capillarization" is the term used to describe the combination of defenestration, basement membrane synthesis and altered expression of endothelial proteins which are seen in various chronic liver diseases including cirrhosis [133], primary biliary cirrhosis [134], chronic hepatitis [108], and viral infections [135]. "Pseudocapillarization" is the term used to describe similar, but distinct age-related changes which occur in the LSEC without the signif-

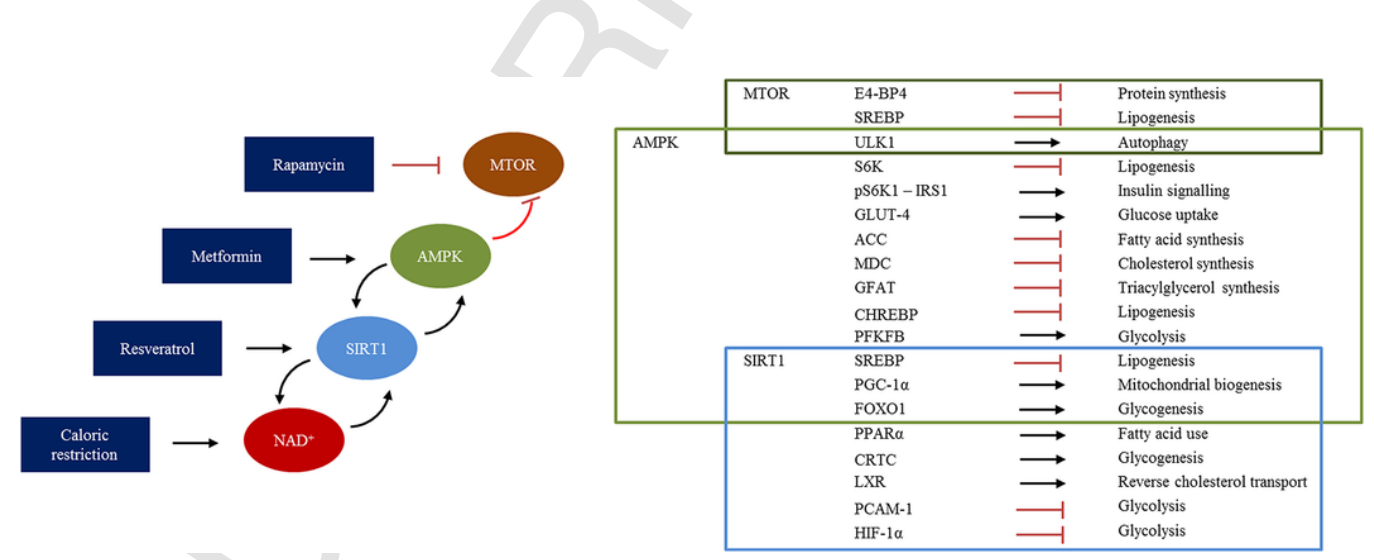

Fig. 1. Drugs that delays the aging process converge on nutrient sensing effectors in the liver. Resveratrol, Metformin, Rapamycin acting on AMPK, mTOR and Sirtuin pathways to regulate ISS and glucose metabolism. All pathways promoted are hepatic. Abbreviations: ACC: acetyl-CoA carboxylase; CHREBP: carbohydrate-responsive element-binding protein; CRTC: creb regulated transcription co-activator 1; E4-BP4: E4 promoter-binding protein 4; FOXO1: forkhead box protein O1; GFAT: glutamine fructose-6-phosphate amidotransferase; GLUT-4: glucose transporter, type 4; HIF-1 1 : hypoxia induction factor 1 $\alpha$; IRS1: insulin receptor substrate 1; LXR: liver X receptor; MDC: macrophage-derived chemokine; PCAM-1: platelet endothelial cell adhesion molecule 1; PFKFB: 6-phosphofructo-2-kinase/fructose-2,6-bisphosphatase: PGC-1 $\alpha$ : peroxisome proliferator-activated receptor gamma co-activator $1 \alpha$; PPAR $\alpha$ : peroxisome proliferator-activated receptor $\alpha$; S6K: ribosomal protein S6 kinase; SREBP; sterol regulatory element-binding proteins; ULK1: unc-51 like autophagy activating kinase 1. References: [43,44,68,98,199,201-207] 


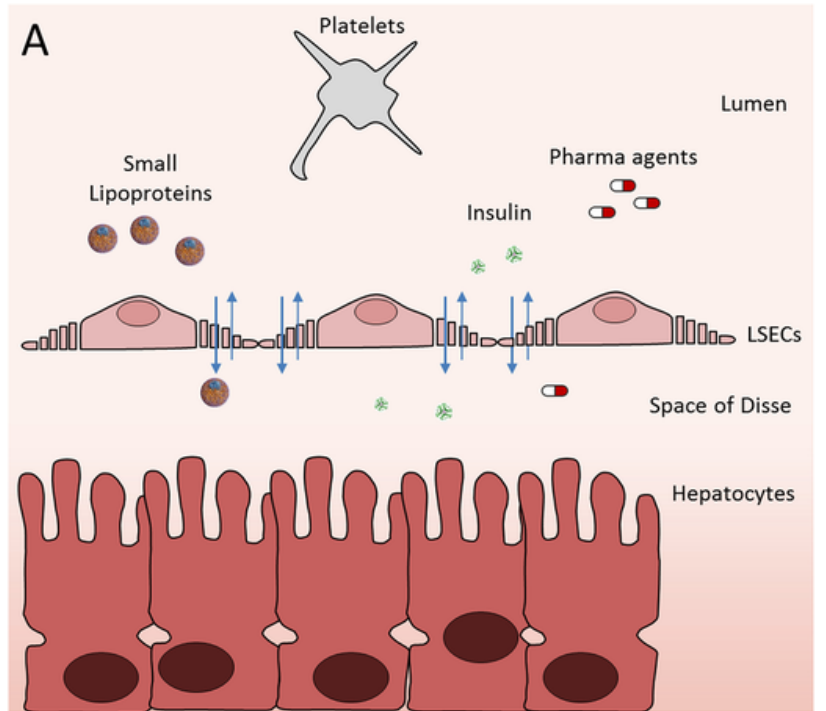

B scanning electron microscopy
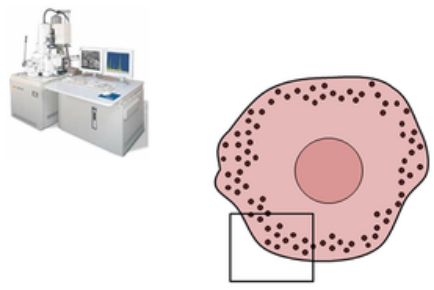

Young 3 month mouse, isolated LSEC

Old 24 month mouse, isolated LSEC
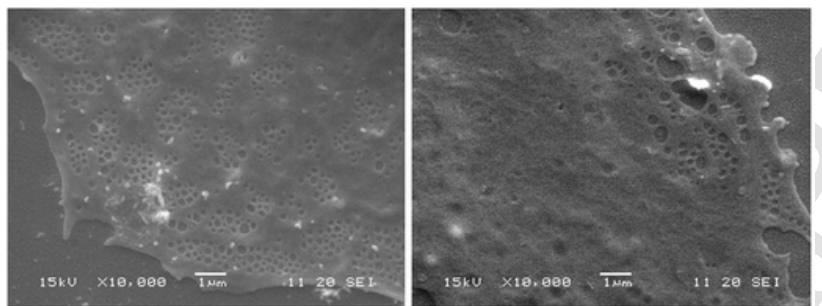

Fig. 2. Loss of filtration and fenestrations in aging mice, schematic of filtration of lipoproteins, insulin and drugs to pass through the blood-liver membrane with scanning electron microscopy images demonstrating defenestration.

icant stellate cell activation or bridging fibrosis seen with chronic liver disease [20,24,25,91,136-140]. Aging is also associated with morphological and/or functional changes with the other cells of the hepatic sinusoid, namely stellate cells and Küpffer cells [21]. LSECs in old age had markedly reduced porosity (\% of LSEC surface area perforated by fenestrations) associated with increased cross-sectional thickness of the LSEC in a variety of species from mice to humans. These age-related morphological changes are accompanied by altered expression of many vascular proteins including von Willebrand's factor, ICAM-1, laminin, caveolin-1 and various collagens on LSEC and in the space of Disse [141] but without other features of liver diseases [142]. Thre is reduced scavenging capacity in old mice [143] at the level of endocytosis, as old LSECs were able to degrade endocytosed ligand equally well as young LSECs once it was endocytosed. However, there was no apparent age-related change in the amount of the receptors responsible for endocytosis (stabilin-1 and -2 scavenger receptors), so it was concluded that thickening of LSEC was retarding the transport of internalized ligand to the endo/lysosomal compartment thus slowing the endocytic process - the "traffic jam" hypothesis [143]. Despite the loss of approximately one third of their endocytic capacity, LSEC remain potent scavengers in aging livers.

\subsection{Implications of age-related defenestration}

Age-related loss of fenestrations has a significant impact on the transfer of substances across the endothelium (Fig. 2). Fenestrations allow passage of smaller lipoproteins including chylomicron remnants, while excluding larger particles such as chylomicrons and platelets. Old age is associated with impaired hepatic clearance of chylomicron remnants and the clinical manifestation of postprandial hypertriglyceridemia. The latter is more closely associated with adverse cardiovascular outcomes in older people than classical dyslipidaemias [136]. Using the multiple indicator dilution method in perfused rat livers, [24] it was shown that the transfer of lipoproteins (average diameter $53 \mathrm{~nm}$ ) across the LSEC was almost totally abolished in livers from old rats. This provides a novel mechanism for age-related dyslipidemia and postprandial hyperlipidaemia [24] and may be a significant contributor to age-related hyperlipidaemia [144] and, hence, vascular disease.

Old age is also associated with insulin resistance and a marked increase in diabetes mellitus. Using multiple indicator dilution methods in perfused livers, [25] it was demonstrated that insulin transfer across LSEC is impaired in old age. Older rats showed a significant reduction in the hepatic volume of insulin distribution, consistent with the restriction of insulin to the vascular space. This was confirmed by whole animal insulin and glucose uptake studies which showed reduced hepatic insulin uptake and concomitant reduced activation of the insulin receptor substrate 1 and insulin pathways in old rats. Measurements of glucose tolerance, HOMA-IR, blood levels of insulin, C-peptide and glucagon showed that the reduced insulin action in the liver was associated with systemic impairment of insulin and glucose metabolism [25]. These findings reveal that fenestrations influence hepatic insulin uptake. Conversely, PDGF-B deficient mice have increased fenestrations which was associated with increased trans-endothelial transport, dramatically lower circulating insulin levels, increased insulin clearance and improved insulin sensitivity [145].

Aging is associated with impaired hepatic metabolism and elimination of many drugs, usually increasing the risk of dose-dependent adverse drug reactions [26]. The reduction in hepatic drug metabolism with aging [146] can in part be explained by changes in the trans-endothelial transport of drugs across the liver sinusoid [147]. For example, hepatic single pass clearance of acetaminophen is reduced in aging rats secondary partly to pseudocapillarization of the LSEC $[148,149]$. This may explain the age-related decrease in susceptibility to paracetamol-induced hepatoxicity but the increase in nephrotoxicity.

Therefore strategies that maintain fenestration porosity during aging, or increase fenestrations in older people have the potential to improve dyslipidemia and hepatic insulin resistance, thereby providing a novel approach for the treatment and prevention of cardiometabolic risk factors in older people [150].

\section{Novel targets to reduce liver aging}

In order to discover drug targets that maintain fenestrations into old age, it is necessary to understand the proximate biological processes that regulate fenestrations. The most potent agents for in- 
creasing fenestrations are vascular endotheial growth factor (VEGF) and various actin cytoskeleton disruptors [151]. These are mechanistically linked because VEGF acts via its effects on the actin cytoskeleton [152]. A major conceptual advance occurred when 3Dstructured illumination super resolution microscopy was used to visualize LSECs [112], revealing the morphological relationship between fenestrations and lipid rafts. It was shown that sieve plates (which are clusters of containing 10-100 fenestrations) were intercalated between thickened areas of membrane identified as lipid rafts [112]. Disruption of lipid rafts and/or actin cytoskeleton increased fenestrations while depletion of non-raft membrane decreased fenestrations. Agents that depleted non-raft membrane prevented actin disruptors from increasing fenestrations, thereby proving that actin disruption increases fenestrations directly by its effects on membrane rafts. VEGF both depleted lipid rafts and increased fenestrations [115] [153]. The results are consistent with a 'sieve-raft' interaction model, where fenestrations form in non-raft regions of endothelial cells once the membrane-stabilizing effects of actin cytoskeleton and membrane rafts are diminished [154]. The sieve-raft model provides a unifying mechanistic pathway for the effects of drugs and other agents that have been reported to increase or decrease fenestrations (Fig. 3).

Prevention of age-related defenestration has been achieved either by using agents that act on nutrient sensing pathways and delay aging more generally; and those that act on specific pathways that appear to regulate fenestrations directly. So far two drugs that delay aging process have been examined and shown to prevent age-related defenestration: resveratrol and metformin.

Resveratrol, which acts on the sirtuin nutrient sensing pathway, has been shown to increase fenestrations in a Werner Syndrome mouse, which is a model for pre-mature aging [155]. Metformin, which acts on the AMPK nutrient sensing pathway, increased fenestration porosity in old mice and improved HOMA-IR and insulin sensitivity [156].

A number of agents that act directly on the pathways associated with the regulation of fenestrations as described above have been tested for their effects on age-related defenestration. The serotonin receptor agonist, 2,5-dimethoxy-4-iodoamphetamine (DOI) promoted increased porosity in young LSECs in vitro [157], as well as in old mice in vivo [158]. The effects of DOI were shown to be modulated by both VEGF dependent and independent mechanisms. Recent data [159] have demonstrated the utility of multiple pharmaceutical agents in promoting increased fenestration diameter and frequency in isolated LSECs from both young and old mice. These agents all act via the pathways previously discussed in this review: nitric oxide dependent pathways (sildenafil and amlodipine); $\mathrm{NAD}^{+}$promotion (nicotinamide mononucleotide); and cell surface death receptor activation (TRAIL) [159].
Lastly, the use of statins has also been shown to promote improvement of autophagy in the setting of liver diseases [53,160-162]. While these drugs have not been specifically tested for this purpose in aging previous findings suggest statin treatment may improve LSEC function through the promotion of KLF-2 similarly to SIRT1 [70] and warrant further investigation.

\subsection{Nanoparticles target the LSEC}

A fundamental challenge in developing pharmacotherapies is targeting the active agent to the desired cell type or tissue. Fortunately, LSECs have unique properties that can be exploited as a drugable target. The LSEC is the most active and efficient endocytic cell in the body [163] and is densely populated with clathrin coated vesicles and numerous endocytic receptors (e.g. mannose receptors, stabilin receptors, Fc gamma-receptor IIb2 $[122,127,164,165])$. This endocytic machinery is highly efficient in uptake and degradation of endogenous and exogenous waste material, including all major classes of biological macromolecules. Therefore, it is not surprising that the LSEC has also proven to be target for the uptake of nanoparticles, particularly those with a diameter between 5-20nm. [130,166,167]. Therefore nanoparticles have been proposed as an efficient way of delivering drugs to the LSEC and other liver cells $[168,169]$ (Fig. 3), reducing dosages, off-target effects and adverse drug reactions. Such drug delivery technology would be ideal for therapeutic agents that regulate fenestrations in the LSEC.

\subsection{Methods for targeted delivery to LSECS}

Several ligands and/or nanoparticles have been investigated for their ability to selectively target the LSEC with a variety of drugs and therapeutic aims.

\subsubsection{Specific ligands}

Hyaluronic acid (HA) is interesting because the expression of its endocytic receptor, stabilin-2, is restricted to LSECs [170], and the vast majority of HA is cleared by the liver. HA is found within the extracellular matrix and synovial fluids of most human tissues, and HA is known to be biocompatible, degradable and non-toxic [171]. A recent study utilized HA-bound nanoparticles in combination with glycyrrhetinic acid (binds to glycyrrhetinic acid receptors expressed on hepatocytes) to promote targeting within the liver [172]. HA-drug conjugation has been successfully developed for the delivery of anticancer drugs to the liver $[173,174]$. also It has been pointed out that an extensive range of substrates (e.g. nanoparticles, nanogels, quantum dots, hydrogels and organic molecules) have been bound to HA to target different cancer types. Several carriers with a high affinity

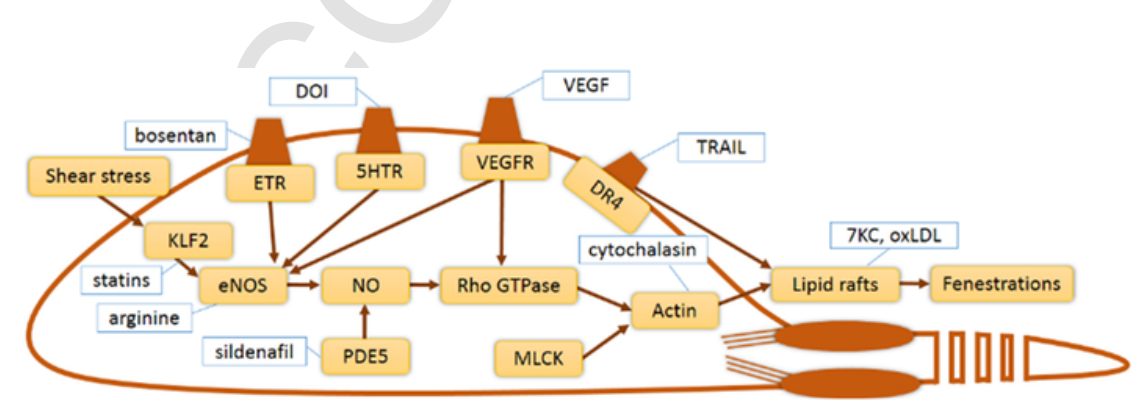

Fig. 3. The sieve-raft model of the regulation of fenestrations, indicating where agents that act on fenestrations have their effects. QDs could be used to deliver these agents specifically to the LSEC in vivo. Abbreviations: 5HTR: serotonin receptor; 7KC: 7-ketocholesterol; DR4: death receptor 4; DOI: 2,5-Dimethoxy-4-iodoamphetamine; ETR: endotheial receptor; KLF2: Krüppel-like Factor 2; MLCK: myosin light chain kinase; oxLDL: oxidised low density lipoprotein; PDE5: phosphodiesterase type 5; TRAIL: 
for stabilin receptor 2 and mannose receptors (HA, oleyamine and polysaccharide chondroitin sulfate) on LSECs were found to facilitate targeted deliver of miRNA to reduce murine colon cancer metastasis [175].

Chemically modified cytokines with natural ligands can target various liver cell types. IL-10 conjugated with thiophosgene-activated mannose-6-phosphate increased liver uptake compared to intravenous injections of IL-10 alone which accumulated in the kidneys [176]. Receptors for mannose/ $\mathrm{N}$-acetyl glucosamine receptors are expressed on hepatocytes, hepatic satellite cells, Küpffer cells and LSECs [169].

Formaldehyde-treated serum albumin (FSA) may have potential for drug delivery to the LSEC because it is avidly taken up by LSECs in vitro and in vivo [177]. In vivo, FSA was almost entirely endocytosed via stabilin- 2 receptors in the LSEC with only $2 \%$ of the dose taken up by other tissues. [178]. FSA is rapidly endocytosed by LSECs within 5-10 mins of intravenous injection and is degraded without hepatic or LSEC toxicity [110,179].

\subsubsection{Nanoparticles and quantum dots}

Nanoparticles range in size from 1-500 nm (by definition, one dimension must be within 1-100nm). Nanoparticles demonstrate (i) high motility in a free state, (ii) high surface area, and (iii) may exhibit quantum effects. Quantum dots (QDs) are a type of nanoparticle that exhibits quantum effects and have a restricted size $(1-20 \mathrm{~nm})$. QDs are semiconductor particles that have different optical and conductive properties than larger sized particles. Nanoparticle and QD uptake within the liver is directed by several properties: size, composition and additional conjugated factors. It has been shown using $\mathrm{Cd} /$ Me QDs, that nanoparticles with a diameter of 3-4nm are endocytosed entirely by LSECs [130]. By comparison, polyethylene glycol (PEG)-bound nanoparticles with a diameter of $50 \mathrm{~nm}$ are taken up by hepatocytes [169]. PEG promotes greater hydrophilic binding and reduces plasma protein binding within the circulation, which reduces phagocytosis by Küpffer cells. Instead PEG binds to mannose/Nacetyl glucosamine receptors expressed on hepatocytes, LSECs and Küpffer cells leading to endocytosis primarily by hepatocytes [169]. $\gamma-\mathrm{Fe}_{2} \mathrm{O}_{3}$ QDs encapsulated within a modified PEG polymer were found to undergo facilitated endocytosis into a ED25 cell line; futhurmore the use of a polymeric micelles was shown to ameliorate toxicity induced by $\mathrm{Fe}_{2} \mathrm{O}_{3}$ QDs .

Basic nanoparticles with a diameter of $>250 \mathrm{~nm}$ are taken up preferentially by Küpffer cells $[180,181]$. This is because nanoparticles of this diameter are too large to pass through fenestrations for hepatocyte uptake; instead they remain in the sinusoidal lumen. Küpffer cells generally phagocytose particles ranging in size from $150-300 \mathrm{~nm}$ in diameter [182]. However, Küpffer cells and LSECs took up 50\% of nanocrystals modified with DSPE-PEG ${ }_{2000}$ that had a diameter of just 4-8nm [183]. It appears that both the size and composition of nanoparticles determine which cell type is preferentially targeted [174].

Mercaptosuccinic acid-capped cadmium telluride/cadmium sulfide $(\mathrm{CdTe} / \mathrm{CdS})$ quantum dots (QDs) have previously been shown to accumulate selectively in the LSEC with minimal endocytosis by Küpffer cells following intravenous injections in vivo in rats [130]. $\mathrm{CdTe} / \mathrm{CdS}$ QDs are negatively charged nanoparticles that are endocytosed by scavenger receptors on LSECs and Küpffer cells [130]. The limitation of these QDs was the failed clearance via the bile three hours post treatment: this was suggested to contribute to their toxicity in LSECs.

Iron oxide nanocrystals or Cd-Selenide/CdS/Zinc-S (core, shell, shell) QDs encapsulated in a amphiphilic polymer (poly(maleic anhy- dride-alt-1-octdencene)) have been used to promote selective uptake into the liver, particularly LSECs [184]. These nanoparticles were non-toxic four weeks post-injection with no changes in cell death detected with a TUNEL assay [184]. However, previous studies with iron oxide nanocrystals highlighted cellular changes in actin and tubulin, and low doses of iron may promote cellular stress pathways based on studies performed in HUVECs [185].

Lipophilic, hydrophobic HA-based nanocapsules target LSECs with apparently less toxicity than other nanoparticles [186]. These nanocapsules selectively target LSECs and pulmonary microvascular endothelial cells. The nanocapsules consist of a liquid oil (oleic acid) core stabilized by hydrophobic modified HA. The structure is between $100-150 \mathrm{~nm}$ in diameter and stable for 15 months in vivo. Both intravenous and oral forms of administration were observed to promote accumulation within the liver within $1 \mathrm{~h}$ for intravenous and within 6ho for oral delivery. Clearance was confirmed in urine of the stable nanocapsule $6 \mathrm{~h}$ post administration with minimal expression in plasma. These characteristics were considered by the authors to be favorable for drug delivery to the liver.

Another interesting nanoparticle for the delivery of agents to the LSEC is MEND (multifunctional envelope-like nanocapsule device). This nanoparticle is composed of cholesterol and PEG-DMG $(1,2-$ dimyristoyl-sn-glycero, methoxy ethylene glycol 2000 ether) combined with a cationic lipid (YSK05) to facilitate the endosomal escape of MEND. MEND is targeted to LSECs and hepatocytes via stearylated KLGR, a novel LDL receptor molecule [187] and its 84$118 \mathrm{~nm}$ diameter. This nanoparticle has been used to deliver siRNA to downregulate Tie2 expression in hepatocytes and LSECs [188] and has been shown to acts via micropinocytosis rather than clathrin-mediated endocytosis.

\section{Summary}

Pathways that regulate the metabolic responses to nutrition by the liver are a plausible target for delaying aging. Diets and drugs that influence the canonical nutrient sensing pathways in the liver are being extensively studied. However, there are also age-related changes in the liver microcirculation that influence the regulation of metabolism by the liver, particularly the metabolism of lipoproteins and insulin sensitivity. There are several drugs and other agents that can increase fenestrations in LSECs from old animals. Such agents, coupled to nanoparticles that are selectively taken up by LSECs, may prove to be a novel therapeutic target for the prevention and treatment of agerelated dyslipidemia and insulin resistance.

\section{References}

[1] J.P. Mackenbach, C.W. Looman, Life expectancy and national income in Europe, 1900-2008: an update of Preston's analysis, Int J Epidemiol 42 (2013) 1100-1110

[2] R. de Cabo, D.G. Le Couteur, The biology of aging, in: D. Kasper, A. Fauci, S. Hauser, D. Longo, J.L. Jameson, J. Loscalzo (Eds.), Harrison's Principles of Internal Medicine, McGraw-Hill Education, New York, NY, 2015, p. 19e.

[3] B.K. Kennedy, S.L. Berger, A. Brunet, J. Campisi, A.M. Cuervo, E.S. Epel, C. Franceschi, G.J. Lithgow, R.I. Morimoto, J.E. Pessin, T.A. Rando, A. Richardson, E.E. Schadt, T. Wyss-Coray, F. Sierra, Geroscience: linking aging to chronic disease, Cell 159 (2014) 709-713.

[4] F. Sierra, Moving geroscience into uncharted waters, J Gerontol A Biol Sci Med Sci (2016).

[5] J.J. Carmona, S. Michan, Biology of healthy aging and longevity, Rev Invest Clin 68 (2016) 7-16.

[6] C. López-Otín, M.A. Blasco, L. Partridge, M. Serrano, G. Kroemer, The hallmarks of aging, Cell 153 (2013) 1194-1217.

[7] M.J. Peters, R. Joehanes, L.C. Pilling, C. Schurmann, K.N. Conneely, J. Powell, E. Reinmaa, G.L. Sutphin, A. Zhernakova, K. Schramm, The tran- 
[8] C.C. Cowie, K.F. Rust, E.S. Ford, M.S. Eberhardt, D.D. Byrd-Holt, C. Li, D.E. Williams, E.W. Gregg, K.E. Bainbridge, S.H. Saydah, L.S. Geiss, Full accounting of diabetes and pre-diabetes in the U.S. population in 1988-1994 and 2005-2006, Diabetes Care 32 (2009) 287-294

[9] R.B. Wallace, P.L. Colsher, Blood lipid distributions in older persons Prevalence and correlates of hyperlipidemia, Ann Epidemiol 2 (1992) 15-21

[10] D. Wahl, V.C. Cogger, S.M. Solon-Biet, R.V.R. Waern, R. Gokarn, T. Pulpitel, R.d. Cabo, M.P. Mattson, D. Raubenheimer, S.J. Simpson, D.G. Le Couteur, Nutritional strategies to optimise cognitive function in the aging brain, Ageing Res Rev 31 (2016) 80-92.

[11] C.M. McCay, M.F. Crowell, L.A. Maynard, The effect of retarded growth upon the length of life span and upon the ultimate body sizeOne figure, $\mathrm{J}$ Nutr 10 (1935) 63-79.

[12] P. Balasubramanian, P.R. Howell, R.M. Anderson, Aging and caloric restriction research: A biological perspective with translational potential, EBioMedicine 21 (2017) 37-44.

[13] L.M. Redman, S.R. Smith, J.H. Burton, C.K. Martin, D. Il'yasova, E. Ravussin, Metabolic slowing and reduced oxidative damage with sustained caloric restriction support the rate of Living and oxidative damage theories of aging, Cell Metab 27 (2018) 805-815, e804

[14] H.-S. Han, G. Kang, J.S. Kim, B.H. Choi, S.-H. Koo, Regulation of glucose metabolism from a liver-centric perspective, Exp Mol Med 48 (2016), e218.

[15] L. Rui, Energy metabolism in the liver, Compr Physiol (2014).

[16] L. Bettedi, L.C. Foukas, Growth factor, energy and nutrient sensing signalling pathways in metabolic ageing, Biogerontology 18 (2017) 913-929.

[17] B. Vollmar, M.D. Menger, The hepatic microcirculation: mechanistic contributions and therapeutic targets in liver injury and repair, Physiol Rev 89 (2009) 1269-1339.

[18] J.J. Meier, M.A. Nauck, Glucagon-like peptide 1(GLP-1) in biology and pathology, Diabetes Metab Res Rev 21 (2005) 91-117.

[19] J.J. Meier, J.D. Veldhuis, P.C. Butler, Pulsatile insulin secretion dictates systemic insulin delivery by regulating hepatic insulin extraction in humans, Diabetes 54 (2005) 1649-1656.

[20] D.G. Le Couteur, V.C. Cogger, A.M. Markus, P.J. Harvey, Z.L. Yin, A.D. Ansselin, A.J. McLean, Pseudocapillarization and associated energy limitation in the aged rat liver, Hepatology 33 (2001) 537-543.

[21] D.G. Le Couteur, A. Warren, V.C. Cogger, B. Smedsrod, K.K. Sorensen, R. De Cabo, R. Fraser, R.S. McCuskey, Old age and the hepatic sinusoid, Anat Rec (Hoboken) 291 (2008) 672-683

[22] H.A. Wynne, L.H. Cope, E. Mutch, M.D. Rawlins, K.W. Woodhouse, O.F. James, The effect of age upon liver volume and apparent liver blood flow in healthy man, Hepatology 9 (1989) 297-301.

[23] A.J. McLean, D.G. Le Couteur, Aging biology and geriatric clinical pharmacology, Pharmacol Rev 56 (2004) 163-184.

[24] S.N. Hilmer, V.C. Cogger, R. Fraser, A.J. McLean, D. Sullivan, D.G. Le Couteur, Age-related changes in the hepatic sinusoidal endothelium impede lipoprotein transfer in the rat, Hepatology 42 (2005) 1349-1354.

[25] M. Mohamad, S.J. Mitchell, L.E. Wu, M.Y. White, S.J. Cordwell, J. Mach, S.M. Solon-Biet, D. Boyer, D. Nines, A. Das, S.Y.C. Li, A. Warren, S.N. Hilmer, R. Fraser, D.A. Sinclair, S.J. Simpson, R. de Cabo, D.G. Le Couteur, V.C. Cogger, Ultrastructure of the liver microcirculation influences hepatic and systemic insulin activity and provides a mechanism for age-related insulin resistance, Aging Cell 15 (2016) 706-715.

[26] S.N. Hilmer, G.M. Shenfield, D.G. Le Couteur, Clinical implications of changes in hepatic drug metabolism in older people, Ther Clin Risk Manag 1 (2005) 151-156.

[27] J.B. Halter, N. Musi, F. McFarland Horne, J.P. Crandall, A. Goldberg, L. Harkless, W.R. Hazzard, E.S. Huang, M.S. Kirkman, J. Plutzky, K.E. Schmader, S. Zieman, K.P. High, Diabetes and cardiovascular disease in older adults: current status and future directions, Diabetes 63 (2014) $2578-2589$

[28] J. Kaur, A comprehensive review on metabolic syndrome, Cardiol Res Pract (2014) (2014) 943162

[29] A. Efeyan, W.C. Comb, D.M. Sabatini, Nutrient-sensing mechanisms and pathways, Nature 517 (2015) 302-310.

[30] A. Aiello, G. Accardi, G. Candore, C.M. Gambino, M. Mirisola, G. Taormina, C. Virruso, C. Caruso, Nutrient sensing pathways as therapeutic targets for healthy ageing, Expert Opin Ther Targets 21 (2017) 371-380.

[31] T. Niccoli, L. Partridge, Ageing as a risk factor for disease, Curr Biol 22 (2012) R741-R752.

[32] F. Bonomini, L.F. Rodella, R. Rezzani, Metabolic syndrome, aging and involvement of oxidative stress, Aging Dis 6 (2015) 109.

[33] V. Guarner, M.E. Rubio-Ruiz, Low-grade systemic inflammation connects aging, metabolic syndrome and cardiovascular disease, In: Aging and Health-A Systems Biology Perspective, Karger Publishers, 2015, pp. 99-106.

[34] D.G. Le Couteur, S.S. Tay, S. Solon-Biet, P. Bertolino, A.C. McMahon, hepatic lymphocytes in aging mice, J Gerontol A Biol Sci Med Sci 70 (2015) 1499-1507.

[35] A. Reeve, E. Simcox, D. Turnbull, Ageing and Parkinson's disease: why is advancing age the biggest risk factor?, Ageing Res Rev 14 (2014) 19-30.

[36] L. Fontana, L. Partridge, V.D. Longo, Extending healthy life span--from yeast to humans, Science 328 (2010) 321-326.

[37] B.P. Hubbard, D.A. Sinclair, Small molecule SIRT1 activators for the treatment of aging and age-related diseases, Trends Pharmacol Sci 35 (2014) $146-154$.

[38] D.G. Le Couteur, A.J. McLachlan, R.J. Quinn, S.J. Simpson, R. de Cabo, Aging biology and novel targets for drug discovery, J Gerontol A Biol Sci Med Sci 67 (2012) 168-174.

[39] A. Martin-Montalvo, E.M. Mercken, S.J. Mitchell, H.H. Palacios, P.L. Mote, M. Scheibye-Knudsen, A.P. Gomes, T.M. Ward, R.K. Minor, M.J. Blouin, M. Schwab, M. Pollak, Y. Zhang, Y. Yu, K.G. Becker, V.A. Bohr, D.K. Ingram, D.A. Sinclair, N.S. Wolf, S.R. Spindler, M. Bernier, R. de Cabo, Metformin improves healthspan and lifespan in mice, Nat Commun 4 (2013) 2192.

[40] D.A. Sinclair, L. Guarente, Small-molecule allosteric activators of sirtuins, Annu Rev Pharmacol Toxicol 54 (2014) 363-380.

[41] D.K. Ingram, M. Zhu, J. Mamczarz, S. Zou, M.A. Lane, G.S. Roth, R. DeCabo, Calorie restriction mimetics: an emerging research field, Aging Cell 5 (2006) 97-108.

[42] S.-i. Imai, L. Guarente, NAD+ and sirtuins in aging and disease, Trends Cell Biol 24 (2014) 464-471.

[43] K. Burkewitz, Y. Zhang, W.B. Mair, AMPK at the nexus of energetics and aging, Cell Metab 20 (2014) 10-25.

[44] H.X. Yuan, Y. Xiong, K.L. Guan, Nutrient sensing, metabolism, and cell growth control, Mol Cell 49 (2013) 379-387.

[45] D.E. Harrison, R. Strong, Z.D. Sharp, J.F. Nelson, C.M. Astle, K. Flurkey, N.L. Nadon, J.E. Wilkinson, K. Frenkel, C.S. Carter, M. Pahor, M.A. Javors, E. Fernandez, R.A. Miller, Rapamycin fed late in life extends lifespan in genetically heterogeneous mice, Nature 460 (2009) 392-395.

[46] R.A. Miller, D.E. Harrison, C.M. Astle, J.A. Baur, A.R. Boyd, R. de Cabo, E. Fernandez, K. Flurkey, M.A. Javors, J.F. Nelson, C.J. Orihuela, S. Pletcher, Z.D. Sharp, D. Sinclair, J.W. Starnes, J.E. Wilkinson, N.L. Nadon, R. Strong, Rapamycin, but not resveratrol or simvastatin, extends life span of genetically heterogeneous mice, J Gerontol A Biol Sci Med Sci 66 (2011) 191-201.

[47] J.B. Mannick, G. Del Giudice, M. Lattanzi, N.M. Valiante, J. Praestgaard, B. Huang, M.A. Lonetto, H.T. Maecker, J. Kovarik, S. Carson, mTOR inhibition improves immune function in the elderly, Sci Transl Med 6 (2014) 268ra179.

[48] D.P.P.R. Group, Reduction in the incidence of type 2 diabetes with lifestyle intervention or metformin, N Engl j Med (2002) (2002) 393-403.

[49] V.R. Aroda, C.A. Christophi, S.L. Edelstein, P. Zhang, W.H. Herman, E. Barrett-Connor, L.M. Delahanty, M.G. Montez, R.T. Ackermann, X. Zhuo, W.C. Knowler, R.E. Ratner, The effect of lifestyle intervention and metformin on preventing or delaying diabetes among women with and without gestational diabetes: The diabetes prevention program outcomes study 10year follow-up, J Clin Endocrinol Metab 100 (2015) 1646-1653.

[50] V.R. Aroda, W.C. Knowler, J.P. Crandall, L. Perreault, S.L. Edelstein, S.L. Jeffries, M.E. Molitch, X. Pi-Sunyer, C. Darwin, B.M. Heckman-Stoddard, Metformin for diabetes prevention: Insights gained from the diabetes prevention program/diabetes prevention program outcomes study, Diabetologia 60 (2017) 1601-1611.

[51] E. Selvin, S. Bolen, H. Yeh, et al., Cardiovascular outcomes in trials of oral diabetes medications: A systematic review, Arch Intern Med 168 (2008) 2070-2080.

[52] A. DeCensi, M. Puntoni, P. Goodwin, M. Cazzaniga, A. Gennari, B. Bonanni, S. Gandini, Metformin and cancer risk in diabetic patients: a systematic review and meta-analysis, Cancer Prev Res 3 (2010) 1451-1461.

[53] J.M. Campbell, S.M. Bellman, M.D. Stephenson, K. Lisy, Metformin reduces all-cause mortality and diseases of ageing independent of its effect on diabetes control: a systematic review and meta-analysis, Ageing Res Rev 40 (2017) 31-44

[54] C.-P. Wang, C. Lorenzo, S.L. Habib, B. Jo, S.E. Espinoza, Differential effects of metformin on age related comorbidities in older men with type 2 diabetes, J Diabetes Complications 31 (2017) 679-686.

[55] J.R. Petrie, N. Chaturvedi, I. Ford, M.C.G.J. Brouwers, N. Greenlaw, T. Tillin, I. Hramiak, A.D. Hughes, A.J. Jenkins, B.E.K. Klein, R. Klein, T.C. Ooi, P. Rossing, C.D.A. Stehouwer, N. Sattar, H.M. Colhoun, Cardiovascular and metabolic effects of metformin in patients with type 1 diabetes (REMOVAL): a double-blind, randomised, placebo-controlled trial, Lancet Diabetes Endocrinol 5 (2017) 597-609.

[56] R. Ladeiras-Lopes, R. Fontes-Carvalho, N. Bettencourt, F. Sampaio, V. Gama, A. Leite-Moreira, Novel therapeutic targets of metformin: metabolic 
V.C. Cogger, F. Colakoglu, A. Warren, A.J. Holmes, N. Pichaud, M. Horan, C. Correa, R.G. Melvin, N. Turner, J.W. Ballard, K. Ruohonen, D. Raubenheimer, S.J. Simpson, The influence of macronutrients on splanchnic and syndrome and cardiovascular disease, Expert Opin Ther Targets 19 (2015) 869-877.
[57] G. Libby, L.A. Donnelly, P.T. Donnan, D.R. Alessi, A.D. Morris, J.M. Evans, New users of metformin are at low risk of incident cancer, Diabetes care 32 (2009) 1620-1625.

[58] M. Guo, J. Mi, Q.M. Jiang, J.M. Xu, YY. Tang, G. Tian, B. Wang, Metformin may produce antidepressant effects through improvement of cognitive function among depressed patients with diabetes mellitus, Clin Exp Pharmacol Physiol 41 (2014) 650-656.

[59] T.P. Ng, L. Feng, K.B. Yap, T.S. Lee, C.H. Tan, B. Winblad, Long-term metformin usage and cognitive function among older adults with diabetes, $\mathrm{J}$ Alzheimers Dis 41 (2014) 61-68

[60] C.-C. Hsu, M.L. Wahlqvist, M.-S. Lee, H.-N. Tsai, Incidence of dementia is increased in type 2 diabetes and reduced by the use of sulfonylureas and metformin, J Alzheimers Dis 24 (2011) 485-493.

[61] C. Cheng, C.-H. Lin, Y.-W. Tsai, C.-J. Tsai, P.-H. Chou, T.-H. Lan, Type 2 diabetes and antidiabetic medications in relation to dementia diagnosis, $\mathrm{J}$ Gerontol A Biol Sci Med Sci 69 (2014) 1299-1305.

[62] M. Wątroba, D. Szukiewicz, The role of sirtuins in aging and age-related diseases, Adv Med Sci 61 (2016) 52-62.

[63] D.A. Sinclair, S.J. Lin, L. Guarente, Life-span extension in yeast, Science 312 (2006) 195-197, author reply 195-197.

[64] K.T. Howitz, K.J. Bitterman, H.Y. Cohen, D.W. Lamming, S. Lavu, J.G. Wood, R.E. Zipkin, P. Chung, A. Kisielewski, L.L. Zhang, B. Scherer, D.A. Sinclair, Small molecule activators of sirtuins extend Saccharomyces cerevisiae lifespan, Nature 425 (2003) 191-196.

[65] J.A. Baur, K.J. Pearson, N.L. Price, H.A. Jamieson, C. Lerin, A. Kalra, V.V. Prabhu, J.S. Allard, G. Lopez-Lluch, K. Lewis, P.J. Pistell, S. Poosala, K.G. Becker, O. Boss, D. Gwinn, M. Wang, S. Ramaswamy, K.W. Fishbein, R.G. Spencer, E.G. Lakatta, D. Le Couteur, R.J. Shaw, P. Navas, P. Puigserver, D.K. Ingram, R. de Cabo, D.A. Sinclair, Resveratrol improves health and survival of mice on a high-calorie diet, Nature 444 (2006) 337-342.

[66] J.C. Milne, P.D. Lambert, S. Schenk, D.P. Carney, J.J. Smith, D.J. Gagne, L. Jin, O. Boss, R.B. Perni, C.B. Vu, J.E. Bemis, R. Xie, J.S. Disch, P.Y. Ng, J.J. Nunes, A.V. Lynch, H. Yang, H. Galonek, K. Israelian, W. Choy, A. Iffland, S. Lavu, O. Medvedik, D.A. Sinclair, J.M. Olefsky, M.R. Jirousek, P.J. Elliott, C.H. Westphal, Small molecule activators of SIRT1 as therapeutics for the treatment of type 2 diabetes, Nature 450 (2007) 712-716.

[67] E.M. Mercken, S.J. Mitchell, A. Martin-Montalvo, R.K. Minor, M. Almeida, A.P. Gomes, M. Scheibye-Knudsen, H.H. Palacios, J.J. Licata, Y. Zhang, K.G. Becker, H. Khraiwesh, J.A. Gonzalez-Reyes, J.M. Villalba, J.A. Baur, P. Elliott, C. Westphal, G.P. Vlasuk, J.L. Ellis, D.A. Sinclair, M. Bernier, R. de Cabo, SRT2104 extends survival of male mice on a standard diet and preserves bone and muscle mass, Aging Cell 13 (2014) 787-796.

[68] M.S. Bonkowski, D.A. Sinclair, Slowing ageing by design: the rise of NAD + and sirtuin-activating compounds, Nat Rev Mol Cell Biol (2016).

[69] K.J. Pearson, J.A. Baur, K.N. Lewis, L. Peshkin, N.L. Price, N. Labinskyy, W.R. Swindell, D. Kamara, R.K. Minor, E. Perez, H.A. Jamieson, Y. Zhang, S.R. Dunn, K. Sharma, N. Pleshko, L.A. Woollett, A. Csiszar, Y. Ikeno, D. Le Couteur, P.J. Elliott, K.G. Becker, P. Navas, D.K. Ingram, N.S. Wolf, Z. Ungvari, D.A. Sinclair, R. de Cabo, Resveratrol delays age-related deterioration and mimics transcriptional aspects of dietary restriction without extending life span, Cell Metab 8 (2008) 157-168.

[70] J. Gracia-Sancho, G. Villarreal Jr, Y. Zhang, G. García-Cardeña, Activation of SIRT1 by resveratrol induces KLF2 expression conferring an endothelial vasoprotective phenotype, Cardiovasc Res 85 (2009) 514-519.

[71] P. Brasnyó, G.A. Molnár, M. Mohás, L. Markó, B. Laczy, J. Cseh, E. Mikolás, I.A. Szijártó, A. Mérei, R. Halmai, Resveratrol improves insulin sensitivity, reduces oxidative stress and activates the Akt pathway in type 2 diabetic patients, Br J Nutr 106 (2011) 383-389.

[72] J.M. Smoliga, J.A. Baur, H.A. Hausenblas, Resveratrol and health-a comprehensive review of human clinical trials, Mol Nutr Food Res 55 (2011) $1129-1141$.

[73] H. Ghanim, C.L. Sia, S. Abuaysheh, K. Korzeniewski, P. Patnaik, A. Marumganti, A. Chaudhuri, P. Dandona, An antiinflammatory and reactive oxygen species suppressive effects of an extract of Polygonum cuspidatum containing resveratrol, J Clin Endocrinol Metab 95 (2010) E1-E8.

[74] T.N. Kjær, M.J. Ornstrup, M.M. Poulsen, H. Stødkilde-Jørgensen, N. Jessen, J.O.L. Jørgensen, B. Richelsen, S.B. Pedersen, No beneficial effects of resveratrol on the metabolic syndrome: A randomized placebo-controlled clinical trial, J Clin Endocrinol Metab 102 (2017) 1642-1651.

[75] S. Chen, X. Zhao, L. Ran, J. Wan, X. Wang, Y. Qin, F. Shu, Y. Gao, L. Yuan, Q. Zhang, Resveratrol improves insulin resistance, glucose and lipid metabolism in patients with non-alcoholic fatty liver disease: a randomized controlled trial, Dig Liver Dis 47 (2015) 226-232.

[76] K. Magyar, R. Halmosi, A. Palfi, G. Feher, L. Czopf, A. Fulop, I. Battyany, B. Sumegi, K. Toth, E. Szabados, Cardioprotection by resveratrol: A human clinical trial in patients with stable coronary artery disease, Clin Hemorheol
[78] C.H. Cottart, V. Nivet-Antoine, J.L. Beaudeux, Review of recent data on the metabolism, biological effects, and toxicity of resveratrol in humans, Mol Nutr Food Res 58 (2014) 7-21.

[79] K. Tsubota, The first human clinical study for NMN has started in Japan, NPJ Aging Mech Dis 2 (2016), 16021.

[80] S. Milman, D.M. Huffman, N. Barzilai, The somatotropic axis in human aging: Framework for the current state of knowledge and future research, Cell Metab 23 (2016) 980-989.

[81] J. Gracia-Sancho, S. Guixé-Muntet, D. Hide, J. Bosch, Modulation of autophagy for the treatment of liver diseases, Expert Opin Investig Drugs 23 (2014) 965-977.

[82] A.M. Cuervo, E. Wong, Chaperone-mediated autophagy: roles in disease and aging, Cell Res 24 (2014) 92.

[83] J. Madrigal-Matute, A.M. Cuervo, Regulation of liver metabolism by autophagy, Gastroenterology 150 (2016) 328-339.

[84] N. Mizushima, B. Levine, A.M. Cuervo, D.J. Klionsky, Autophagy fights disease through cellular self-digestion, Nature 451 (2008) 1069.

[85] R.C. Russell, H.-X. Yuan, K.-L. Guan, Autophagy regulation by nutrient signaling, Cell Res 24 (2014) 42.

[86] T. Laeger, T.M. Henagan, D.C. Albarado, L.M. Redman, G.A. Bray, R.C Noland, H. Munzberg, S.M. Hutson, T.W. Gettys, M.W. Schwartz, C.D. Morrison, FGF21 is an endocrine signal of protein restriction, J Clin Invest 124 (2014) 3913-3922.

[87] S.M. Solon-Biet, V.C. Cogger, T. Pulpitel, M. Heblinski, D. Wahl, A.C. McMahon, A. Warren, J. Durrant-Whyte, K.A. Walters, J.R. Krycer, F. Ponton, R. Gokarn, J.A. Wali, K. Ruohonen, A.D. Conigrave, D.E. James, D. Raubenheimer, C.D. Morrison, D.G. Le Couteur, S.J. Simpson, Defining the nutritional and metabolic context of FGF21 using the geometric framework, Cell Metab 24 (2016) 555-565.

[88] M.D. Chau, J. Gao, Q. Yang, Z. Wu, J. Gromada, Fibroblast growth factor 21 regulates energy metabolism by activating the AMPK-SIRT1-PGC-1alpha pathway, PNAS 107 (2010) 12553-12558.

[89] T. Xie, P.S. Leung, Fibroblast growth factor 21: a regulator of metabolic disease and health span, Am J Physiol Endocrinol Metab 313 (2017) E292-e302.

[90] D.G. Le Couteur, A.J. McLean, The aging liver. Drug clearance and an oxygen diffusion barrier hypothesis, Clinical Pharmacokinetics 34 (1998) 359-373.

[91] A.J. McLean, V.C. Cogger, G.C. Chong, A. Warren, A.M. Markus, J.E. Dahlstrom, D.G. Le Couteur, Age-related pseudocapillarization of the human liver, J Pathol 200 (2003) 112-117.

[92] K.W. Woodhouse, H.A. Wynne, Age-related changes in liver size and hepatic blood flow. The influence on drug metabolism in the elderly, Clinical Pharmacokinetics 15 (1988) 287-294.

[93] H.A. Wynne, O.F. James, The ageing liver, Age Ageing 19 (1990) 1-3

[94] V.C. Cogger, M. Mohamad, S.M. Solon-Biet, A.M. Senior, A. Warren, J.N. O'Reilly, B.T. Tung, D. Svistounov, A.C. McMahon, R. Fraser, D. Raubenheimer, A.J. Holmes, S.J. Simpson, D.G. Le Couteur, Dietary macronutrients and the aging liver sinusoidal endothelial cell, Am J Physiol Heart Circ Physiol 310 (2016) H1064-H1070.

[95] M.C. Yang, A.J. McLean, L.P. Rivory, D.G. Couteur, Hepatic disposition of neurotoxins and pesticides, Basic Clin Pharmacol Toxicol 87 (2000) 286-291.

[96] S.X. Cao, J.M. Dhahbi, P.L. Mote, S.R. Spindler, Genomic profiling of short-and long-term caloric restriction effects in the liver of aging mice, PNAS 98 (2001) 10630-10635.

[97] K.W. Chung, E.K. Lee, D.H. Kim, H.J. An, N.D. Kim, D.S. Im, J. Lee, B.P. Yu, H.Y. Chung, Age-related sensitivity to endotoxin-induced liver inflammation: Implication of inflammasome/IL- $1 \beta$ for steatohepatitis, Aging Cell 14 (2015) 524-533.

[98] A. Picca, A.M.S. Lezza, Regulation of mitochondrial biogenesis through TFAM-mitochondrial DNA interactions: Useful insights from aging and calorie restriction studies, Mitochondrion 25 (2015) 67-75.

[99] V.C. Cogger, S.N. Hilmer, D. Sullivan, M. Muller, R. Fraser, D.G. Le Couteur, Hyperlipidemia and surfactants: the liver sieve is a link, Atherosclerosis 189 (2006) 273-281.

[100] F. Sheedfar, S.D. Biase, D. Koonen, M. Vinciguerra, Liver diseases and aging: friends or foes?, Aging Cell 12 (2013) 950-954.

[101] E. Maslak, A. Gregorius, S. Chlopicki, Liver sinusoidal endothelial cells (LSECs) function and NAFLD; NO-based therapy targeted to the liver, Pharmacol Rep 67 (2015) 689-694.

[102] M. Pasarín, V. La Mura, J. Gracia-Sancho, H. García-Calderó, A. Rodríguez-Vilarrupla, J.C. García-Pagán, J. Bosch, J.G. Abraldes, Sinusoidal endothelial dysfunction precedes inflammation and fibrosis in a model of NAFLD, PLoS One 7 (2012), e32785.

[103] M. Miyao, H. Kotani, T. Ishida, C. Kawai, S. Manabe, H. Abiru, K. Tamaki, 
Microcirc 50 (2012) 179-187.

[77] N. Xia, A. Daiber, U. Förstermann, H. Li, Antioxidant effects of resveratrol in the cardiovascular system, Br J Pharmacol 174 (2017) 1633-1646.
Pivotal role of liver sinusoidal endothelial cells in NAFLD/NASH progression, Lab Invest 95 (2015) 1130.
[104] R. Fraser, V.C. Cogger, B. Dobbs, H. Jamieson, A. Warren, S.N. Hilmer, D.G. Le Couteur, The liver sieve and atherosclerosis, Pathology 44 (2012) 181-186.

[105] E. Wisse, An electron microscopic study of the fenestrated endothelial lining of rat liver sinusoids, J Ultrastruct Res 31 (1970) 125-150.

[106] R. Fraser, B.R. Dobbs, G.W. Rogers, Lipoproteins and the liver sieve: the role of the fenestrated sinusoidal endothelium in lipoprotein metabolism, atherosclerosis, and cirrhosis, Hepatology 21 (1995) 863-874.

[107] A. Warren, D.G. Le Couteur, R. Fraser, D.G. Bowen, G.W. McCaughan, P. Bertolino, T lymphocytes interact with hepatocytes through fenestrations in murine liver sinusoidal endothelial cells, Hepatology 44 (2006) 1182-1190.

[108] A. Warren, P. Bertolino, V. Benseler, R. Fraser, G.W. McCaughan, D.G. Le Couteur, Marked changes of the hepatic sinusoid in a transgenic mouse model of acute immune-mediated hepatitis, Journal of Hepatology 46 (2007) 239-246.

[109] D. Svistounov, A. Oteiza, S.N. Zykova, K.K. Sorensen, P. McCourt, A.J. McLachlan, R.S. McCuskey, B. Smedsrod, Hepatic disposal of advanced glycation end products during maturation and aging, Exp Gerontol 48 (2013) 549-556.

[110] K.K. Sørensen, P.A. McCourt, T. Berg, C. Crossley, D. LeCouteur, K. Wake, B. Smedsrød, The scavenger endothelial cell - a new player in homeostasis and immunity, Am J Physiol Regul Integr Comp Physiol 303 (2012) R1217-R1230.

[111] J. Simon-Santamaria, C.H. Rinaldo, P. Kardas, R. Li, I. Malovic, K. Elvevold, P. McCourt, B. Smedsrod, H.H. Hirsch, K.K. Sorensen, Efficient uptake of blood-borne BK and JC polyomavirus-like particles in endothelial cells of liver sinusoids and renal vasa recta, PLoS One 9 (2014), e111762.

[112] V.C. Cogger, G.P. McNerney, T. Nyunt, L.D. DeLeve, P. McCourt, B Smedsrod, D.G. Le Couteur, T.R. Huser, Three-dimensional structured illumination microscopy of liver sinusoidal endothelial cell fenestrations, J Struct Biol 171 (2010) 382-388.

[113] V. Mönkemöller, C.I. Øie, P. Heimann, C. Kaltschmidt, B. Kaltschmidt, P.A. McCourt, T.R. Huser, W. Hubner, Multimodal nanoscopy reveals unique structural dynamics of liver endothelial cells, In: International Conference on Nanoscopy, 2016.

[114] V. Monkemoller, M. Schuttpelz, P. McCourt, K. Sorensen, B. Smedsrod, T. Huser, Imaging fenestrations in liver sinusoidal endothelial cells by optical localization microscopy, Phys Chem Chem Phys 16 (2014) 12576-12581.

[115] D. Svistounov, A. Warren, G.P. McNerney, D.M. Owen, D. Zencak, S.N. Zykova, H. Crane, T. Huser, R.J. Quinn, B. Smedsrod, D.G. Le Couteur, V.C. Cogger, The Relationship between fenestrations, sieve plates and rafts in liver sinusoidal endothelial cells, PLoS One 7 (2012), e46134.

[116] I. Øie Cristina, V. Mönkemöller, W. Hübner, M. Schüttpelz, H. Mao, S. Ahluwalia Balpreet, R. Huser Thomas, P. McCourt, New ways of looking at very small holes - using optical nanoscopy to visualize liver sinusoidal endothelial cell fenestrations, Nanophotonics 7 (2018) 575 .

[117] P.A. McCourt, A. Oteiza, B. Cao, S.K. Nilsson, Isolation of murine bone marrow scavenging sinusoidal endothelial cells, Methods Mol Biol 1235 (2015) 59-71.

[118] H. Qian, S. Johansson, P. McCourt, B. Smedsrod, M. Ekblom, S. Johansson, Stabilins are expressed in bone marrow sinusoidal endothelial cells and mediate scavenging and cell adhesive functions, Biochem Biophys Res Commun 390 (2009) 883-886.

[119] R. Li, P. McCourt, K. Schledzewski, S. Goerdt, G. Moldenhauer, X. Liu, B. Smedsrod, K.K. Sorensen, Endocytosis of advanced glycation end-products in Bovine choriocapillaris endothelial cells, Microcirculation (2009) 1-16.

[120] P.A. McCourt, How does the hyaluronan scrap-yard operate?, Matrix Biol 18 (1999) 427-432.

[121] P.A. McCourt, S. Gustafson, On the adsorption of hyaluronan and ICAM-1 to modified hydrophobic resins, Int J Biochem Cell Biol 29 (1997) $1179-1189$.

[122] P.A. McCourt, B.H. Smedsrod, J. Melkko, S. Johansson, Characterization of a hyaluronan receptor on rat sinusoidal liver endothelial cells and its functional relationship to scavenger receptors, Hepatology 30 (1999) 1276-1286.

[123] B. Smedsrod, H. Pertoft, S. Eriksson, J.R. Fraser, T.C. Laurent, Studies in vitro on the uptake and degradation of sodium hyaluronate in rat liver endothelial cells, Biochem J 223 (1984) 617-626.

[124] B. Hansen, P. Longati, K. Elvevold, G.I. Nedredal, K. Schledzewski, R. Olsen, M. Falkowski, J. Kzhyshkowska, F. Carlsson, S. Johansson, B. Smedsrod, S. Goerdt, S. Johansson, P. McCourt, Stabilin-1 and stabilin-2 are both directed into the early endocytic pathway in hepatic sinusoidal endothelium via interactions with clathrin/AP-2, independent of ligand binding, Exp Cell Res 303 (2005) 160-173.

[125] D.N. Svistounov, T.J. Berg, P.A. McCourt, S.N. Zykova, K.H. Elvevold, R. endothelial cells is mediated by FcgammaRIIb2, Hepatology 46 (2007) 871-884.

[127] I. Malovic, K.K. Sorensen, K.H. Elvevold, G.I. Nedredal, S. Paulsen, A.V. Erofeev, B.H. Smedsrod, P.A. McCourt, The mannose receptor on murine liver sinusoidal endothelial cells is the main denatured collagen clearance receptor, Hepatology 45 (2007) 1454-1461.

[128] B. Smedsrød, S. Johansson, H. Pertoft, Studies in vivo and in vitro on the uptake and degradation of soluble collagen a1(I) chains in rat liver endothelial and Kupffer cells, Biochem J 228 (1985) 415-424.

[129] R. Li, A. Oteiza, K.K. Sorensen, P. McCourt, R. Olsen, B. Smedsrod, D. Svistounov, Role of liver sinusoidal endothelial cells and stabilins in elimination of oxidized low-density lipoproteins, Am J Physiol Gastrointest Liver Physiol 300 (2011) G71-G81.

[130] X. Liang, J.E. Grice, Y. Zhu, D. Liu, W.Y. Sanchez, Z. Li, D.H. Crawford, D.G. Le Couteur, V.C. Cogger, X. Liu, Z.P. Xu, M.S. Roberts, Intravital multiphoton imaging of the selective uptake of water-dispersible quantum dots into sinusoidal liver cells, Small 11 (2015) 1711-1720.

[131] C. Godfrey, L.R. Desviat, B. Smedsrod, F. Pietri-Rouxel, M.A. Denti, P. Disterer, S. Lorain, G. Nogales-Gadea, V. Sardone, R. Anwar, S. El Andaloussi, T. Lehto, B. Khoo, C. Brolin, W.M. van Roon-Mom, A. Goyenvalle, V. Aartsma-Rus, Delivery is key: lessons learnt from developing splice-switching antisense therapies, EMBO Mol Med 9 (2017) 545-557.

[132] L.D. DeLeve, Liver sinusoidal endothelial cells in hepatic fibrosis, Hepatology $61(2015)$ 1740-1746.

[133] P. Onori, S. Morini, A. Franchitto, R. Sferra, D. Alvaro, E. Gaudio, Hepatic microvascular features in experimental cirrhosis: a structural and morphometrical study in CC14-treated rats, Journal of Hepatology 33 (2000) $555-563$.

[134] T. Mori, T. Okanoue, Y. Sawa, N. Hori, M. Ohta, K. Kagawa, Defenestration of the sinusoidal endothelial-cell in a rat model of cirrhosis, Hepatology 17 (1993) 891-897.

[135] A.M. Steffan, C.A. Pereira, A. Bingen, M. Valle, J.P. Martin, F. Koehren, C Royer, J.L. Gendrault, A. Kirn, Mouse hepatitis-virus type-3 infection provokes a decrease in the number of sinusoidal endothelial-cell fenestrae both in-vivo and in-vitro, Hepatology 22 (1995) 395-401.

[136] D.G. Le Couteur, R. Fraser, V.C. Cogger, A.J. McLean, Hepatic pseudocapillarisation and atherosclerosis in ageing, Lancet 359 (2002) 1612-1615.

[137] V.C. Cogger, D. Svistounov, A. Warren, S. Zykova, R.G. Melvin, S.M. Solon-Biet, A.C. Reilly, J.W. McMahon, R. Ballard, D.G. De Cabo, M. Lebel Le Couteur, Liver aging and pseudocapillarization in a Werner syndrome mouse model, J Gerontol A Biol Sci Med Sci 69 (2014) 1076-1086.

[138] V.C. Cogger, A. Warren, R. Fraser, M. Ngu, A.J. McLean, D.G. Le Couteur, Hepatic sinusoidal pseudocapillarization with aging in the non-human primate, Exp Gerontol 38 (2003) 1101-1107.

[139] A. Warren, P. Bertolino, V.C. Cogger, A.J. McLean, R. Fraser, D.G. Le Couteur, Hepatic pseudocapillarization in aged mice, Exp Gerontol 40 (2005) $807-812$.

[140] J.N. O'Reilly, V.C. Cogger, D.G. Le Couteur, Old age is associated with ultrastructural changes in isolated rat liver sinusoidal endothelial cells, J Electron Microsc (Tokyo) 59 (2010) 65-69.

[141] D.G. Le Couteur, A. Warren, V.C. Cogger, B. Smedsrod, K.K. Sorensen, R. De Cabo, R. Fraser, R.S. Mccuskey, Old age and the hepatic sinusoid, Anat. Rec. 291 (2008) 672-683.

[142] A. Warren, V.C. Cogger, R. Fraser, L.D. Deleve, R.S. McCuskey, D.G. Le Couteur, The effects of old age on hepatic stellate cells, Curr Gerontol Geriatr Res 2011 (2011), 439835.

[143] J. Simon, I. Malovic, A. Warren, A. Oteiza, D. LeCouteur, B. Smedsrød, P.A. Mccourt, K.K. Sørensen, Age-related changes in scavenger receptormediated endocytosis in rat liver sinusoidal endothelial cells, J Gerontol A Biol Sci Med Sci 65 (2010) 951-960.

[144] H.H. Liu, J.J. Li, Aging and dyslipidemia: a review of potential mechanisms, Ageing Res Rev 19 (2015) 43-52.

[145] S.M. Raines, O.C. Richards, L.R. Schneider, K.L. Schueler, M.E. Rabaglia, A.T. Oler, D.S. Stapleton, G. Genove, J.A. Dawson, C. Betsholtz, A.D. Attie, Loss of PDGF-B activity increases hepatic vascular permeability and enhances insulin sensitivity, Am J Physiol Endocrinol Metab 301 (2011) E517-E526.

[146] S.N. Hilmer, G. Ford, General principles of pharmacology, in: J.B. Halter, J.G. Ouslander, M.E. Tinetti, S. Studenski, K.P. High, S. Asthana (Eds.), Hazzard's Geriatric Medicine and Gerontology, McGraw-Hill, 2009, pp. $103-122$.

[147] S.J. Mitchell, A.E. Kane, S.N. Hilmer, Age-related changes in the hepatic pharmacology and toxicology of paracetamol, Curr Gerontol Geriatr Res (2011) (2011) 624156 . 
Nagai, S. Horiuchi, B.H. Smedsrod, Lack of recognition of Nepsilon-(carboxymethyl)lysine by the mouse liver reticulo-endothelial system: implications for pathophysiology, Biochem Biophys Res Commun 309 (2003) 786-791.

[126] S.A. Mousavi, M. Sporstol, C. Fladeby, R. Kjeken, N. Barois, T. Berg, Receptor-mediated endocytosis of immune complexes in rat liver sinusoidal
[148] J. Mach, A. Huizer-Pajkos, V.C. Cogger, C. McKenzie, D.G. Le Couteur, B.E. Jones, R. de Cabo, S.N. Hilmer, The effect of aging on acetaminophen pharmacokinetics, toxicity and Nrf2 in Fischer 344 rats, J Gerontol A Biol Sci Med Sci 69 (2014) 387-397.

[149] S.J. Mitchell, A. Huizer-Pajkos, V.C. Cogger, A.J. McLachlan, D.G. Le Couteur, B. Jones, R. de Cabo, S.N. Hilmer, Age-related pseudocapillariza- tion of the liver sinusoidal endothelium impairs the hepatic clearance of acetaminophen in rats, J Gerontol A Biol Sci Med Sci 66 (2011) 400-408.

[150] D.G. Le Couteur, V.C. Cogger, R.S. McCuskey, B. Smedsrod, K.K. Sorensen, A. Warren, R. Fraser, Age-related changes in the liver sinusoidal endothelium: a mechanism for dyslipidemia, Ann N Y Acad Sci 1114 (2007) 79-87.

[151] V.C. Cogger, D.G. Le Couteur, Fenestrations in the liver sinusoidal endothelial cell, in: I.M. Arias, A. Wolkoff, J.L. Boyer, D.A. Shafritz, N. Fausto, H. Alter, A. Cohen (Eds.), The Liver: Biology and Pathobiology, John Wiley \& Sons, Ltd, Hoboken, NJ, 2009, pp. 387-404.

[152] V.C. Cogger, I.M. Arias, A. Warren, A.C. McMahon, D.L. Kiss, V.M. Avery, D.G. Le Couteur, The response of fenestrations, actin, and caveolin-1 to vascular endothelial growth factor in SK Hep1 cells, Am J Physiol Gastrointest Liver Physiol 295 (2008) G137-g145.

[153] J. Rodriguez-Vita, M. Morales-Ruiz, Down the liver sinusoidal endothelial cell (LSEC) hole. Is there a role for lipid rafts in LSEC fenestration?, Hepatology 57 (2013) 1272-1274.

[154] V.C. Cogger, U. Roessner, A. Warren, R. Fraser, D.G. Le Couteur, A SieveRaft Hypothesis for the regulation of endothelial fenestrations, Comput Struct Biotechnol J 8 (2013), e201308003.

[155] A. Labbé, C. Garand, V.C. Cogger, E.R. Paquet, M. Desbiens, D.G. Le Couteur, M. Lebel, Resveratrol improves insulin resistance hyperglycemia and hepatosteatosis but not hypertriglyceridemia, inflammation, and life span in a mouse model for Werner syndrome, J Gerontol A Biol Sci Med Sci 66 (2010) 264-278.

[156] I. Alfaras, S.J. Mitchell, H. Mora, D.R. Lugo, A. Warren, I. Navas-Enamorado, V. Hoffmann, C. Hine, J.R. Mitchell, D.G. Le Couteur, Health benefits of late-onset metformin treatment every other week in mice, NPJ Aging Mech Dis 3 (2017) 16.

[157] V.C. Cogger, S.J. Mitchell, A. Warren, R. de Cabo, D.G. Le Couteur, Agerelated loss of responsiveness to 2,5-dimethoxy-4-iodoamphetamine in liver sinusoidal endothelial cells, J Gerontol A Biol Sci Med Sci (2013).

[158] K. Furrer, A. Rickenbacher, Y. Tian, W. Jochum, A.G. Bittermann, A. Kach, B. Humar, R. Graf, W. Moritz, P.A. Clavien, Serotonin reverts age-related capillarization and failure of regeneration in the liver through a VEGF-dependent pathway, PNAS 108 (2011) 2945-2950.

[159] N.J. Hunt, G. Lockwood, A. Warren, H. Mao, P. McCourt, D.G. Le Couteur, V.C. Cogger, Manipulating fenestrations in young and old liver sinusoidal endothelial cells, Am J Physiol Gastrointest Liver Physiol (2018), Accepted.

[160] G. Kim, S.Y. Jang, E. Han, Y.h. Lee, S.y. Park, C.M. Nam, E.S. Kang, Effect of statin on hepatocellular carcinoma in patients with type 2 diabetes: A nationwide nested case-control study, Int J Cancer 140 (2017) 798-806.

[161] K.-Y. Kim, H.-J. Jang, Y.R. Yang, K.-I. Park, J. Seo, I.-W. Shin, T.-I. Jeon, S.C. Ahn, P.-G. Suh, T.F. Osborne, SREBP-2/PNPLA8 axis improves nonalcoholic fatty liver disease through activation of autophagy, Sci Rep 6 (2016) 35732

[162] S. Guixé-Muntet, F.C. de Mesquita, S. Vila, V. Hernández-Gea, C. Peralta, J.C. García-Pagán, J. Bosch, J. Gracia-Sancho, Cross-talk between autophagy and KLF2 determines endothelial cell phenotype and microvascular function in acute liver injury, Journal of Hepatology 66 (2017) 86-94.

[163] K.K. Sorensen, J. Simon-Santamaria, R.S. McCuskey, B. Smedsrod, Liver sinusoidal endothelial cells, Compr Physiol 5 (2015) 1751-1774

[164] O. Politz, A. Gratchev, P.A. McCourt, K. Schledzewski, P. Guillot, S. Johansson, G. Svineng, P. Franke, C. Kannicht, J. Kzhyshkowska, P. Longati, F.W. Velten, S. Johansson, S. Goerdt, Stabilin-1 and -2 constitute a novel family of fasciclin-like hyaluronan receptor homologues, Biochem J 362 (2002) 155-164

[165] K. Elvevold, J. Simon-Santamaria, H. Hasvold, P. McCourt, B. Smedsrod, K.K. Sorensen, Liver sinusoidal endothelial cells depend on mannose receptor-mediated recruitment of lysosomal enzymes for normal degradation capacity, Hepatology 48 (2008) 2007-2015.

[166] Y. Sato, H. Hatakeyama, M. Hyodo, H. Harashima, Relationship between the physicochemical properties of lipid nanoparticles and the quality of siRNA delivery to liver cells, Mol Ther (2015)

[167] S. Alidori, R. L. Bowman, D Yarilin, Y Romin, A. Barlas, J J. Mulvey, S. Fujisawa, K. Xu, A. Ruggiero, V. Riabov, D.L. Thorek, H.D. Ulmert, E.J. Brea, K. Behling, J. Kzhyshkowska, K. Manova-Todorova, D.A. Scheinberg, M.R. McDevitt, Deconvoluting hepatic processing of carbon nanotubes, Nat Commun 7 (2016), 12343.

[168] M. Bartneck, K.T. Warzecha, F. Tacke, Therapeutic targeting of liver inflammation and fibrosis by nanomedicine, Hepatobiliary Surg Nutr 3 (2014) 364-376.

[169] J.-H. Kang, R. Toita, M. Murata, Liver cell-targeted delivery of therapeutic
[171] S. Arpicco, P. Milla, B. Stella, F. Dosio, Hyaluronic acid conjugates as vectors for the active targeting of drugs, genes and nanocomposites in cancer treatment, Molecules 19 (2014) 3193-3230.

[172] X. Wang, X. Gu, H. Wang, Y. Sun, H. Wu, S. Mao, Synthesis, characterization and liver targeting evaluation of self-assembled hyaluronic acid nanoparticles functionalized with glycyrrhetinic acid, Eur J Pharm Sci 96 (2017) 255-262.

[173] F. Dosio, S. Arpicco, B. Stella, E. Fattal, Hyaluronic acid for anticancer drug and nucleic acid delivery, ADDR 97 (2016) 204-236.

[174] Y. Zhang, J. Pan, Q. Xu, H. Li, J. Wang, C. Zhang, G. Hong, Synthesis and in vitro experiments of carcinoma vascular endothelial targeting polymeric nano-micelles combining small particle size and supermagnetic sensitivity, Int J Med Sci 15 (2018) 498-506.

[175] J. Marquez, I. Fernandez-Piñeiro, M.J. Araúzo-Bravo, G. Poschmann, K. Stühler, A.M. Khatib, A. Sanchez, F. Unda, G. Ibarretxe, I. Bernales, Targeting liver sinusoidal endothelial cells with mi R-20a-loaded nanoparticles reduces murine colon cancer metastasis to the liver, Int J Cancer (2018).

[176] H. Rachmawati, C. Reker-Smit, M.N. Lub-de Hooge, A. van LoenenWeemaes, K. Poelstra, L. Beljaars, Chemical modification of interleukin-10 with mannose 6-phosphate groups yields a liver-selective cytokine, Drug Metab Dispos 35 (2007) 814-821.

[177] L. Stradiot, S. Verhulst, T. Roosens, C. Øie, I. Moya, G. Halder, I. Mannaerts, L. van Grunsven, Functionality based method for simultaneous isolation of rodent hepatic sinusoidal cells, Biomaterials (2017).

[178] M.R. de Oliveira, S.F. Nabavi, A. Manayi, M. Daglia, Z. Hajheydari, S.M. Nabavi, Resveratrol and the mitochondria: from triggering the intrinsic apoptotic pathway to inducing mitochondrial biogenesis, a mechanistic view, BBA - General Subjects 1860 (2016) 727-745.

[179] K.K. Sørensen, J. Melkko, B. Smedsrød, Scavenger-receptor-mediated endocytosis in endocardial endothelial cells of Atlantic cod Gadus morhua, $\mathrm{J}$ Exp Biol 201 (1998) 1707-1718.

[180] S.R. Popielarski, S. Hu-Lieskovan, S.W. French, T.J. Triche, M.E. Davis, A nanoparticle-based model delivery system to guide the rational design of gene delivery to the liver. 2 . In vitro and in vivo uptake results, Bioconjug Chem 16 (2005) 1071-1080.

[181] M.E. Davis, D.M. Shin, Nanoparticle therapeutics: an emerging treatment modality for cancer, Nat Rev Drug Discov 7 (2008) 771-782.

[182] J.-K. Park, T. Utsumi, Y.-E. Seo, Y. Deng, A. Satoh, W.M. Saltzman, Y. Iwakiri, Cellular distribution of injected PLGA-nanoparticles in the liver, Nanomedicine 12 (2016) 1365-1374.

[183] K. Sigfridsson, U. Skantze, P. Skantze, S. Johansson, I. Grant, B. Smedsrød, B. Fuglesteg, K. Elvevold, L. Lindfors, Nanocrystal formulations of a poorly soluble drug. 1 . In vitro characterization of stability, stabilizer adsorption and uptake in liver cells, Int J Pharm 518 (2017) 29-40.

[184] A. Carambia, B. Freund, D. Schwinge, O.T. Bruns, S.C. Salmen, H. Ittrich, R. Reimer, M. Heine, S. Huber, C. Waurisch, Nanoparticle-based autoantigen delivery to Treg-inducing liver sinusoidal endothelial cells enables control of autoimmunity in mice, Journal of Hepatology 62 (2015) 1349-1356.

[185] X. Wu, Y. Tan, H. Mao, M. Zhang, Toxic effects of iron oxide nanoparticles on human umbilical vein endothelial cells, Int J Cancer 5 (2010) 385.

[186] J. Szafraniec, A. Błażejczyk, E. Kus, M. Janik, G. Zając, J. Wietrzyk, S. Chlopicki, S. Zapotoczny, Robust oil-core nanocapsules with hyaluronatebased shells as promising nanovehicles for lipophilic compounds, Nanoscale 9 (2017) 18867-18880.

[187] A. Akhter, Y. Hayashi, Y. Sakurai, N. Ohga, K. Hida, H. Harashima, A liposomal delivery system that targets liver endothelial cells based on a new peptide motif present in the ApoB-100 sequence, Int J Pharm 456 (2013) 195-201.

[188] A. Akhter, Y. Hayashi, Y. Sakurai, N. Ohga, K. Hida, H. Harashima, Ligand density at the surface of a nanoparticle and different uptake mechanism: Two important factors for successful siRNA delivery to liver endothelial cells, Int J Pharm 475 (2014) 227-237.

[189] P.P. Karunadharma, N. Basisty, D.F. Dai, Y.A. Chiao, E.K. Quarles, E.J. Hsieh, D. Crispin, J.H. Bielas, N.G. Ericson, R.P. Beyer, Subacute calorie restriction and rapamycin discordantly alter mouse liver proteome homeostasis and reverse aging effects, Aging Cell 14 (2015) 547-557.

[190] M. Jové, A. Naudí, O. Ramírez-Núñez, M. Portero-Otín, C. Selman, D.J. Withers, R. Pamplona, Caloric restriction reveals a metabolomic and lipidomic signature in liver of male mice, Aging Cell 13 (2014) 828-837.

[191] W.H. Boylston, A. Gerstner, J.H. DeFord, M. Madsen, K. Flurkey, D.E. Harrison, J. Papaconstantinou, Altered cholesterologenic and lipogenic transcriptional profile in livers of aging Snell dwarf (Pit1dw/dwJ) mice, Aging Cell 3 (2004) 283-296. 
molecules, Crit Rev Biotechnol 36 (2016) 132-143.

[170] M. Falkowski, K. Schledzewski, B. Hansen, S. Goerdt, Expression of stabilin-2, a novel fasciclin-like hyaluronan receptor protein, in murine sinusoidal endothelia, avascular tissues, and at solid/liquid interfaces, Histochem Cell Biol 120 (2003) 361-369.
[192] A. Kuhla, T. Blei, R. Jaster, B. Vollmar, Aging is associated with a shift of fatty metabolism toward lipogenesis, J Gerontol A Biol Sci Med Sci 66A (2011) 1192-1200.

[193] S. Ding, J. Jiang, G. Zhang, Y. Bu, G. Zhang, X. Zhao, Resveratrol and caloric restriction prevent hepatic steatosis by regulating SIRT1-autophagy pathway and alleviating endoplasmic reticulum stress in high-fat diet-fed rats, PLoS One 12 (2017), e0183541.
[194] N. Martinez-Lopez, D. Athonvarangkul, R. Singh, Autophagy and aging, In: Longevity Genes, Springer, 2015, pp. 73-87.

[195] N. Barzilai, S. Banerjee, M. Hawkins, W. Chen, L. Rossetti, Caloric restriction reverses hepatic insulin resistance in aging rats by decreasing visceral fat, J Clin Invest 101 (1998) 1353

[196] W. Zhang, S. Patil, B. Chauhan, S. Guo, D.R. Powell, J. Le, A. Klotsas, R. Matika, X. Xiao, R. Franks, FoxO1 regulates multiple metabolic pathways in the liver effects on gluconeogenic, glycolytic, and lipogenic gene expression, J Biol Chem 281 (2006) 10105-10117.

[197] C. Sun, F. Zhang, X. Ge, T. Yan, X. Chen, X. Shi, Q. Zhai, SIRT1 improves insulin sensitivity under insulin-resistant conditions by repressing PTP1B, Cell Metab 6 (2007) 307-319.

[198] M. Tiikkainen, A.-M. Häkkinen, E. Korsheninnikova, T. Nyman, S. Mäkimattila, H. Yki-Järvinen, Effects of rosiglitazone and metformin on liver fat content, hepatic insulin resistance, insulin clearance, and gene expression in adipose tissue in patients with type 2 diabetes, Diabetes 53 (2004) 2169-2176.

[199] J.T. Rodgers, C. Lerin, W. Haas, S.P. Gygi, B.M. Spiegelman, P. Puigserver, Nutrient control of glucose homeostasis through a complex of PGC-1 $\alpha$ and SIRT1, Nature 434 (2005) 113-118.
[200] J.M. Dhahbi, P.L. Mote, J. Wingo, J.B. Tillman, R.L. Walford, S.R. Spindler, Calories and aging alter gene expression for gluconeogenic, glycolytic, and nitrogen-metabolizing enzymes, Am J Physiol Endocrinol Metab 277 (1999) E352-E360.

[201] M. Shimobayashi, M.N. Hall, Making new contacts: the mTOR network in metabolism and signalling crosstalk, Nat Rev Mol Cell Biol 15 (2014) $155-162$.

[202] M. Cornu, V. Albert, M.N. Hall, mTOR in aging, metabolism, and cancer, Curr Opin Genetics Dev 23 (2013) 53-62.

[203] M.M. Mihaylova, R.J. Shaw, The AMPK signalling pathway coordinates cell growth, autophagy and metabolism, Nat Cell Biol 13 (2011) 1016-1023.

[204] M. Foretz, B. Viollet, Regulation of hepatic metabolism by AMPK, Journal of Hepatology 54 (2011) 827-829.

[205] H.-C. Chang, L. Guarente, SIRT1 and other sirtuins in metabolism, Trends Endocrinol Metab 25 (2014) 138-145.

[206] R.H. Houtkooper, E. Pirinen, J. Auwerx, Sirtuins as regulators of metabolism and healthspan, Nat Rev Mol Cell Biol 13 (2012) 225-238.

[207] J. Kim, M. Kundu, B. Viollet, K.-L. Guan, AMPK and mTOR regulate autophagy through direct phosphorylation of Ulk1, Nat Cell Biol 13 (2011) 132-141. 
